\title{
Enhanced tumor delivery and antitumor response of doxorubicin-loaded albumin nanoparticles formulated based on a Schiff base
}

This article was published in the following Dove Press journal:

International Journal of Nanomedicine

12 August 2016

Number of times this article has been viewed

Fang Li, ${ }^{1,2, *}$ Chunli Zheng, ${ }^{1, *}$ Junbo Xin, ${ }^{2}$ Fangcheng Chen,' Hua Ling, ${ }^{3}$ Linlin Sun, ${ }^{4}$ Thomas J Webster, ${ }^{4,5}$ Xin Ming, ${ }^{6}$ Jianping Liu'

'School of Pharmacy, China Pharmaceutical University, Nanjing, ${ }^{2}$ School of Pharmacy, Yancheng Vocational Institute of Health Sciences, Yancheng, People's Republic of China; ${ }^{3}$ School of Pharmacy, Hampton University, Hampton, VA, ${ }^{4}$ Department of Chemical Engineering, Northeastern University, Boston, MA, USA; ${ }^{5}$ Center of Excellence for Advanced Materials Research, King Abdulaziz University, Jeddah, Saudi Arabia; ${ }^{6}$ Division of Molecular Pharmaceutics, UNC Eshelman School of Pharmacy, University of North Carolina, Chapel Hill, NC, USA

*These authors contributed equally to this work

Correspondence: Xin Ming Division of Molecular Pharmaceutics, UNC Eshelman School of Pharmacy, University of North Carolina, 1310 Kerr Hall, CB757I, UNC-CH, Chapel Hill, NC 27599, USA

Tel + I 9198432277

Email xming@email.unc.edu

Jianping Liu

School of Pharmacy, China

Pharmaceutical University, 24

Tongjiaxiang, Nanjing, 210009 ,

People's Republic of China

Tel +862585338217

Email liujianpingljp@hotmail.com
Abstract: A novel method was developed here to prepare albumin-based nanoparticles (NPs) for improving the therapeutic and safety profiles of chemotherapeutic agents. This approach involved crosslinking bovine serum albumin (BSA) using a Schiff base-containing vanillin, into NPs and loading doxorubicin (DOX) into the NPs by incubation. The resultant NPs (DOX-BSA-V-NPs) displayed a particle size of $100.5 \pm 1.3 \mathrm{~nm}$ with a zeta potential of $-23.05 \pm 1.45 \mathrm{mV}$ and also showed high drug-loading efficiency and excellent stability with respect to storage and temperature. The encapsulation of DOX into the BSA-V-NPs was confirmed by dynamic scanning calorimetry and Raman spectroscopy. DOX-BSA-V-NPs exhibited a significantly faster DOX release at $\mathrm{pH} 6.5$ than $\mathrm{pH} 7.4$, as well as in a solution with a higher glutathione concentration. In vitro studies showed that the cellular uptake of DOX-BSA-V-NPs was time-dependent, concentration-dependent, and faster than free DOX, while the cytotoxicity of DOX-BSA-VNPs $\left(\mathrm{IC}_{50}\right.$ value of $3.693 \mu \mathrm{g} / \mathrm{mL}$ ) was superior to free DOX ( $\mathrm{IC}_{50}$ value of $\left.4.007 \mu \mathrm{g} / \mathrm{mL}\right)$. More importantly, DOX-BSA-V-NPs showed a longer mean survival time of 24.83 days, a higher tumor inhibition rate of $56.66 \%$, and a decreased distribution in the heart than other DOX formulations in animal studies using a tumor xenograft model. Thus, the vanillin-based albumin NPs were shown here to be a promising carrier for tumor-targeted delivery of chemotherapeutic agents and, thus, should be further studied.

Keywords: doxorubicin, albumin nanoparticles, Schiff base, tumor delivery, anticancer response

\section{Introduction}

Doxorubicin (DOX), the most commonly used anthracycline, has an antineoplastic effect on breast, lung, stomach, lymph, and ovary carcinomas. ${ }^{1}$ However, severe toxicities (such as myelosuppression, mucositis, and cardiomyopathy) have limited its application in medicine. ${ }^{2,3}$ The side effects associated with anticancer drugs can be remarkably reduced by encapsulating them in nanocarriers. ${ }^{4,5}$ DOX has been encapsulated in liposomes or pegylated (stealth) liposomes, leading to numerous products on the market (Myocet ${ }^{\circledR}$ [Cephalon, Inc., Frazer, PA, USA] and Doxil ${ }^{\circledR}$ [Janssen Biotech, Inc., Horsham, PA, USA]/Caelyx ${ }^{\circledR}$ [Ben Venue Laboratories, Inc., Bedford, OH, USA]), and liposomal DOX shows a lower drug-related toxicity and similar anticancer activity compared to free DOX. ${ }^{6-10}$ However, the pegylation of liposomes has resulted in a side effect called hand-foot syndrome ${ }^{11}$ (also known as palmar plantar erythrodysesthesia) due to the leakage of DOX from capillaries in the palms of the hands and soles of the feet. Hence, improving the therapeutic index of DOX has been long pursued. ${ }^{10}$

Albumin NPs are a most promising carrier for drug delivery due to their biocompatibility, biodegradability, and tumor targeting ability because of albumin's 
high affinity with the glycoprotein receptor gp60 and secreted proteins that are acidic and rich in cysteine. The Schiff base has recently attracted considerable attention due to its therapeutic potential, ${ }^{12}$ including antibacterial, ${ }^{13,14}$ anticancer, ${ }^{15,16}$ and antiproliferative activities. ${ }^{17}$ Bovine serum albumin (BSA), a low-cost and readily available globular protein, exhibits $76 \%$ homology with human serum albumin (HSA), ${ }^{18}$ which is always used to substitute HSA. Vanillin, a water-soluble aromatic compound, has been widely used as a food supplement and is generally regarded to be safe. In our previous work, we developed a thermally driven self-assembly method to prepare BSA-vanillin NPs (BSA-V-NPs), ${ }^{19}$ and this method was based on the Schiff base which was formed by the chemical reaction between the amino groups of BSA and the aldehyde groups of vanillin in an aqueous environment. Moreover, hydrogen bonds can be formed between the hydroxyl groups of vanillin and albumin. With vanillin as a nontoxic crosslinker, the resultant BSA-V-NPs are more stable due to the existence of a Schiff base and hydrogen bonds. Besides, a cytotoxicity study indicated that the BSA-V-NPs have potential anticancer activity.

The primary goal of the present study was to improve the therapeutic index of DOX by encapsulating it in the BSA-VNPs. Tumor delivery and anticancer activities were evaluated using human gastric cancer BGC-823 cells and in xenograft tumor-bearing mice. Control formulations included free DOX and DOX-loaded vanillin-free BSA-NPs (DOX-BSA-NPs). Tumor delivery was investigated using cellular uptake and in vivo distribution studies, while the anticancer activity was further verified by cytotoxicity assays, a survivability study, tumor suppression, and histological examination in tumor resections after treatment.

\section{Materials and methods}

BSA, L-glutathione (GSH), rhodamin B isothiocyanate (RBITC), and 1,1'-dioctadecyl-3,3,3',3'-tetramethylindo tricarbocyanine iodide (DiR) were purchased from Sigma-Aldrich Co. (St Louis, MO, USA). Vanillin was obtained from Aladdin Industrial Corporation (Shanghai, People's Republic of China). Doxorubicin hydrochloride was supplied by Dalian Meilun Biotech Co. Ltd (Dalian, People's Republic of China). Nystatin was purchased from HeFei BoMei Biotechnology Co. Ltd (Hefei, People's Republic of China). Lysotracker Green DND-26, RPMI1640 medium, fetal bovine serum, and antibiotics (penicillin 10,000 units $/ \mathrm{mL}$, streptomycin $10,000 \mu \mathrm{g} / \mathrm{mL}$ ) were obtained from Thermo Fisher Scientific (Waltham, MA, USA). 4',
6-Diamidino-2-phenylindole (DAPI) was purchased from Vector Laboratories, Inc. (Burlingame, CA, USA). Methanol and acetonitrile were of high performance liquid chromatography (HPLC) grade, other chemicals and reagents were of analytical grade and used as received.

\section{Preparation of DOX-BSA-V-NPs}

BSA-V-NPs were prepared as reported previously. ${ }^{19}$ Briefly, $250 \mathrm{mg}$ of BSA and $14.4 \mathrm{mg}$ of vanillin were dissolved in $50 \mathrm{~mL}$ of deionized water and heated at $70^{\circ} \mathrm{C}$ for 2 hours. Generally, $5 \mathrm{mg} / \mathrm{mL}$ of a $\mathrm{DOX} \cdot \mathrm{HCl}$ aqueous solution was added into the BSA-V-NPs at a proper weight ratio of DOX to BSA. The mixture was stored in the dark for 24 hours after adjusting the $\mathrm{pH}$ with sodium hydroxide $(\mathrm{NaOH})$. The obtained NP solution was stored at $4^{\circ} \mathrm{C}$ before use. The DiR-labeled BSA-V-NPs (DiR-BSA-V-NPs) were prepared with the same procedure and purified by dialyzing against phosphate-buffered saline (PBS) buffer. ${ }^{20}$ The vanillin-free DOX-BSA-NPs were also prepared by incubating DOX with BSA-NPs in the dark for 24 hours.

RBITC-labeled BSA-V-NPs (RBITC-BSA-V-NPs) were fabricated as previously reported. ${ }^{19}$ Briefly, RBITC-labeled BSA (RBITC-BSA) was synthesized by dissolving BSA in carbonate buffer and incubating with RBITC for 2 hours. After dialyzing against deionized water for 24 hours, the RBITC-BSA was obtained by lyophilization..$^{21}$ After dissolving RBITC-BSA and vanillin in deionized water, RBITCBSA-V-NPs were obtained by heating the mixture at $70^{\circ} \mathrm{C}$ for 2 hours.

\section{Determination of particle size and zeta potential}

The particle size of the NPs was determined by dynamic light scattering (DLS) (Brookhaven Instrument Corporation, Holtsville, NY, USA) with a fixed scattering angle of $90^{\circ}$, while the zeta potential of the NPs was measured by the Zetaplus zeta potential analyzer (Brookhaven Instrument Corporation) at $25^{\circ} \mathrm{C}$.

\section{Determination of drug loading efficiency and drug encapsulation efficiency}

The free DOX was separated by a centrifugal-ultrafiltration method, and the DOX content was calculated by the absorbance at $480 \mathrm{~nm}$ using a calibration curve. ${ }^{22}$ The amount of free BSA in the supernatant of the BSA colloidal solution after centrifugation $(39,120 \times g)$ at $4^{\circ} \mathrm{C}$ for 60 minutes was determined using the Coomassie ${ }^{\circledR}$ protein assay reagent kit (Nanjing Jiancheng Bioengineering Institute, Jiangsu, 
People's Republic of China). ${ }^{23}$ Drug loading efficiency (DLE) and drug encapsulation efficiency (DEE) of the NPs were calculated by the following equations: ${ }^{24}$

$$
\begin{gathered}
\operatorname{DLE}(\%)=\frac{m_{\text {encapsulated DOX }}}{m_{\text {encapsulated DOX }}+m_{\text {self-assembly BSA }}} \times 100 \% \\
\operatorname{DEE~}(\%)=\frac{m_{\text {encapsulated DOX }}}{m_{\text {DOX in feed }}} \times 100 \%
\end{gathered}
$$

\section{Morphology observation}

The colloidal solutions of BSA-V-NPs and DOX-BSAV-NPs were separately diluted with deionized water to a proper concentration and one droplet was placed on the copper grid. After staining with $2 \%$ phosphotungstic acid for 30 seconds, a transmission electron microscope (TEM, H-7650; Hitachi Ltd., Tokyo, Japan) was used to capture images of the BSA-NPs.

\section{Circular dichroism spectroscopy, dynamic scanning calorimetry, and Raman spectroscopy}

To investigate the protein's structural changes, circular dichroism (CD) spectra were obtained on a Jasco J-810 Spectrometer (Jasco, Tokyo, Japan) at room temperature over a wavelength range of 190-260 nm with a scan rate of $50 \mathrm{~nm} / \mathrm{min}$, response time of 1 second, and BSA concentration of $0.1 \mathrm{mg} / \mathrm{mL}$. PBS buffer $(\mathrm{pH} 7.4)$ was used as the solvent.

Thermal analysis of the DOX, BSA-V-NPs, DOX-BSAV-NPs, and mixture of DOX and BSA-V-NPs were performed on a differential scanning calorimeter (DSC Q2000; TA Instruments, Wilmington, DE, USA) with an integrated autosampler. Accurately weighed samples were placed into aluminum containers and measured using a programmed scan speed of $10^{\circ} \mathrm{C} / \mathrm{min}$ from room temperature to $250^{\circ} \mathrm{C}$ under a nitrogen atmosphere.

The colloidal solutions of BSA-V-NPs and DOX-BSAV-NPs were lyophilized for 24 hours after removing the free BSA and DOX. The Raman spectra of DOX, BSA-V-NPs, DOX-BSA-V-NPs, and the mixture of DOX and BSA-V-NPs were recorded by a DXR Raman microscope (Thermo Fisher Scientific) equipped with a $780 \mathrm{~nm}$ externally stabilized diode laser. The digital camera was cooled at $-40^{\circ} \mathrm{C}$. Spectra were acquired over the wavelength range of 3,350-50 $\mathrm{cm}^{-1}$ with an exposure time of 2 seconds, 30 times, and using a 50x objective and laser power of $24 \mathrm{~mW}$.

\section{Stability of DOX-BSA-V-NPs}

The stability of DOX-BSA-V-NPs was investigated by determining the particle size as a function of time..$^{25}$ The samples were dissolved in $0.9 \% \mathrm{NaCl}$ and $5 \%$ glucose with a protein concentration of $1 \mathrm{mg} / \mathrm{mL}$ and stored at $37^{\circ} \mathrm{C}$ for 48 hours. ${ }^{26}$ At various time points, the hydrodynamic diameters were measured by DLS (Brookhaven Instrument Corporation). Meanwhile, the DOX-BSA-V-NPs were also stored at $4{ }^{\circ} \mathrm{C}$ for 2 months and at $40^{\circ} \mathrm{C}$ for 10 days.

\section{Doxorubicin release in vitro}

To obtain in vitro drug release profiles, PBS ( $\mathrm{pH} 7.4$ and pH 6.5), $10 \mu \mathrm{M}$ GSH (pH 7.4), and $20 \mathrm{mM} \mathrm{GSH}$ (pH 6.5) solutions were used as the release media. The solution of DOX-BSA-V-NPs (1.8 mL) was dialyzed (MWCO 14 kDa; Jinsui Biotechnology Co., Ltd., Shanghai, People's Republic of China) against $23.2 \mathrm{~mL}$ of the release buffer at $37^{\circ} \mathrm{C}$ with constant shaking. Three milliliters of the release buffer were withdrawn at specific intervals and the same volume of fresh medium was added. Each experiment was repeated twice and the average data were reported.

\section{Cellular uptake and uptake mechanism}

Human gastric cancer BGC-823 cells (Ethical approval to use this human cancer cell line was not required by China Pharmaceutical University.) were seeded in 24-well microplates at $5.0 \times 10^{4}$ cells/well and were incubated at $37^{\circ} \mathrm{C}$ in a $5 \% \mathrm{CO}_{2}$ incubator for 24 hours. Then, the cells were incubated with the same concentration of free DOX and DOX-BSA-V-NPs. After incubation for $0.5,1,2,4$, and 8 hours, the medium was removed and the cells were washed thrice with cold PBS buffer and were fixed with paraformaldehyde for 20 minutes. Finally, the uptake of free DOX and DOX-BSA-V-NPs was observed by an inverted fluorescence microscope (Olympus Corporation, Tokyo, Japan). To investigate the influence of DOX concentration on cellular uptake, drug concentrations over the range of $0.39-12.48 \mu \mathrm{g} / \mathrm{mL}$ were administered to the cells. To semiquantitatively determine the uptake amount, BGC-823 cells were seeded and treated as described earlier. Then, cells were trypsinized, supplemented with $0.5 \mathrm{~mL}$ of cell culture medium, and harvested by centrifugation at $180 \times g$ for 5 minutes. The cell pellet was rinsed three times with cold PBS buffer, resuspended in $0.5 \mathrm{~mL}$ of PBS, and analyzed using flow cytometry (BD, Franklin Lakes, NJ, USA). To trace cellular uptake behavior, BGC-823 cells were also seeded on laser confocal dishes and incubated for 24 hours, then DOX and DOX-BSA-V-NPs were added separately. After washing thrice with cold PBS buffer and staining 
for 20 minutes with DAPI, the samples were observed with a confocal laser scanning microscope (CLSM, TCS-SP5; Leica Microsystems, Wetzlar, Germany).

Endocytosis uptake of BSA-V-NPs was investigated by endo-lysosomal labeling and pharmacological endocytic inhibitors. For this, BGC-823 cells were seeded on the laser confocal dishes and incubated for 24 hours. Subsequently, a RBITC-BSA-V-NPs solution was added and incubated for 4 hours. After removing the NP solution, the cells were washed with cold PBS buffer and incubated with LysoTracker Green for another 2 hours. After washing thrice and staining for 20 minutes with DAPI, the samples were observed with a CLSM (TCS-SP5). To further reveal the uptake pathways of BSA-V-NPs, BGC-823 cells were preincubated with the endocytic inhibitors sucrose $(450 \mathrm{mM}$, inhibiting clathrinmediated endocytosis) and nystatin $(25 \mu \mathrm{g} / \mathrm{mL}$ inhibiting caveolae-mediated endocytosis), respectively. ${ }^{21,27}$ After removing the inhibitor solution, the cells were washed thrice and further treated with DOX-BSA-V-NPs for 4 hours. Finally, the cells were washed, fixed, and observed using an inverted fluorescence microscope (Olympus). The cells without inhibitor treatment were used as a control.

\section{Cytotoxicity assay}

The cytotoxicity of DOX-BSA-V-NPs was determined using a cell counting kit-8 (CCK-8) assay (Dojido, Kumamoto, Japan) according to the manufacturer's instructions. BGC-823 cells were seeded on 96-well microplates at $1.0 \times 10^{4}$ cells/well and incubated in a $5 \% \mathrm{CO}_{2}$ incubator at $37^{\circ} \mathrm{C}$ for 24 hours to attach to the bottom. After removing the culture media from the wells, the DOX-BSA-V-NPs solution was diluted using 1640 cell culture medium at a series of concentrations added into the wells. After incubating at $37^{\circ} \mathrm{C}$ for 48 hours, the drug solution was removed and the CCK-8 solution was added. Then, the microplates were incubated for another 1 hour and the optical density (OD) of each well was determined by an Infinite M200 Pro microplate reader (Tecan, Mannedorf, Switzerland). A free Dox solution at the same concentration was used as a control. The cell viability $(\mathrm{CV})$ was calculated by the equation: $\mathrm{CV}(\%)=\mathrm{OD}_{\text {sample }} / \mathrm{OD}_{\text {blank }} \times 100 \%$, while the inhibitory concentration $50 \%\left(\mathrm{IC}_{50}\right)$ value was calculated by SPSS $^{\circledR}$ Statistics for Windows version 18.0 software (IBM Corporation, Armonk, NY, USA).

\section{Animals and tumor xenograft models}

Institute of Cancer Research mice (male, 25-30 g) were obtained from Qinglongshan Animal Breeding Field (Jiangsu, People's Republic of China). The experiments were conducted in full compliance with the Guide for Care and Use of Laboratory Animals and approved by the China Pharmaceutical University. The tumor-bearing mice were inoculated in the subcutaneous dorsa with $100 \mu \mathrm{L}$ of hepatocellular carcinoma (Heps) cells $\left(2 \times 10^{6}\right.$ cells/mouse) ${ }^{28}$ Tumor volume was calculated using the equation: $V=a \times b^{2} / 2$, where $a$ and $b$ are the length and width of the tumor, respectively. ${ }^{25}$

\section{Biodistribution examination in vivo}

Heps tumor xenograft mice were used for the in vivo biodistribution study. A noninvasive fluorescent imaging technique was used to explore the tumor-targeting ability of BSA-VNPs. A DiR-BSA-V-NPs solution in $0.1 \mathrm{~mL}$ was injected to the Heps tumor-bearing mouse with a DiR dose of $5 \mathrm{mg} / \mathrm{kg}$ via the tail vein. After $0.5,1,4,6,12$, and 24 hours, the anesthetized mouse was introduced into the chamber and near-infrared fluorescence (NIRF) images were captured by a DXS 4000PRO System (Kodak, Rochester, NY, USA) under the same condition. ${ }^{28}$

The mice were randomly assigned to three treatment groups with 24 males in each group and intravenously administered separately with free DOX, DOX-BSA-NPs, and DOX-BSAV-NPs with a DOX dose of $5 \mathrm{mg} / \mathrm{kg}$ after 7 days of the inoculation. The mice were sacrificed at $0.5,1,2,4,6,12,24$, and 48 hours after injection ( $n=3$ at each time point). Subsequently, the tumor and heart tissue were collected and measured. After homogenization of the tissues with saline, DOX was extracted by mixing acetonitrile:methanol:concentrated $\mathrm{HCl}$ (66:33:2, v:v:v) with the homogenate. Following 2 minutes of vortex and centrifugation at $12,000 \times g$ for 10 minutes, quantitative analysis of the DOX concentration in the supernatant was performed by HPLC. ${ }^{28}$ The data were calculated according to the calibration curve and normalized to the tissue weight.

\section{In vivo antitumor efficacy}

For the in vivo survival study, the mice were randomly divided into four treatment groups with six males in each group. The inoculation day was recorded as day 0 , and the treatments were started 5 days later. Normal saline, free DOX, DOXBSA-NPs, and DOX-BSA-V-NPs solutions were injected with a DOX dose of $5 \mathrm{mg} \cdot \mathrm{kg}^{-1} \cdot \mathrm{day}^{-1}$ for 3 days, respectively. The survival time of each mouse was recorded. Mean survival time (MST) of each group and the increase in lifespan (ILS) were calculated by the following equations: ${ }^{15}$

$$
\begin{gathered}
\text { MST }=\frac{\sum \text { Survival time of each mice in a group }}{\text { Total number of mice }} \\
\text { ILS }=\left[\frac{\mathrm{MST}_{\text {treated }}-\mathrm{MST}_{\text {control }}}{\mathrm{MST}_{\text {control }}}\right] \times 100
\end{gathered}
$$


For the in vivo tumor inhibition test, the Heps tumorbearing mice were also intravenously administered with normal saline, free DOX, DOX-BSA-NPs, and DOX-BSAV-NPs after 3 days of the inoculation with a DOX dose of $5 \mathrm{mg} \cdot \mathrm{kg}^{-1} \cdot \mathrm{day}^{-1}$ for 3 days. After 10 days of inoculation, the animals were sacrificed by cervical dislocation..$^{22,24}$ Subsequently, dissection was done, and the tumors and hearts were removed for the following studies. The solid tumors were harvested and measured, while the hearts and tumors were sectioned for histological evaluation by hematoxylin and eosin (HE) staining. The tumor inhibition rate (TIR) was calculated by the equation: ${ }^{29}$

$$
\operatorname{TIR}(\%)=\left(1-\frac{\overline{\mathrm{V}}_{\text {treated }}}{\overline{\mathrm{V}}_{\text {control }}}\right) \times 100 \%
$$

where $\overline{\mathrm{V}}_{\text {treated }}$ is the average tumor volume of the treated group, and $\bar{V}_{\text {control }}$ is the average tumor volume of the normal saline group.

\section{Statistical analysis}

Data are presented as mean \pm SD and were analyzed by Student's $t$-tests to determine the significance of differences between the groups. Statistical significance was set at $P<0.05$ and $P<0.01$.

\section{Results and discussion Preparation of DOX-BSA-V-NPs}

BSA-V-NPs were fabricated by a thermal driven self-assembly method, in which the $\mathrm{pH}, \mathrm{BSA} /$ vanillin ratio, BSA concentration, and heating temperature were all important factors. The optimized preparation conditions were as follows: deionized water ( $\mathrm{pH} 6$ ) as a reaction solution; $\mathrm{BSA} /$ vanillin $(\mathrm{mol} / \mathrm{mol})$ at a $1: 25 \mathrm{ratio}$; BSA concentration at $5 \mathrm{mg} / \mathrm{mL}$, and heating temperature at $70^{\circ} \mathrm{C}$. The particle size, polydispersity index (PDI), and zeta potential of the BSA-V-NPs were $106.4 \pm 1.8 \mathrm{~nm}, 0.167 \pm 0.024$, and $-20.49 \pm 0.72 \mathrm{mV}$, respectively.

The DOX-BSA-V-NPs were prepared by incubating DOX $\cdot \mathrm{HCl}$ with the BSA-V-NPs. To simplify the description, the concentration of BSA-V-NPs was denoted by BSA concentration. The initial $\mathrm{pH}$ of the mixture of DOX $\cdot \mathrm{HCl}$ and BSA-V-NPs $(1: 10, \mathrm{w} / \mathrm{w})$ without adjustment was around 5, where the charge of NPs was almost neutral. Hence, the particles aggregated and the particle size reached 2,106.3 $\pm 116.4 \mathrm{~nm}$ (Table 1). As the $\mathrm{pH}$ value increased, both the negative charges in the system and the concentration of unprotonated DOX molecules increased. Therefore, the
Table I DLS, DLE, and DEE results of DOX-BSA-V-NPs prepared at different $\mathrm{pH}$ values with a $\mathrm{BSA} / \mathrm{DOX} \cdot \mathrm{HCl}$ ratio $(\mathrm{w} / \mathrm{w})$ of $10: 1$

\begin{tabular}{lllll}
\hline $\mathbf{p H}$ & Particle size $\mathbf{n m}$ & PDI & DLE (\%) & DEE (\%) \\
\hline Initial $\mathrm{pH}$ & $2,106.3 \pm \mathrm{I} 16.4$ & $0.349 \pm 0.018$ & - & - \\
6.8 & $100.5 \pm 3.5$ & $0.139 \pm 0.037$ & $8.23 \pm 1.49$ & $83.49 \pm 5.04$ \\
7.4 & $92.7 \pm 1.8$ & $0.163 \pm 0.013$ & $9.09 \pm 0.41$ & $88.60 \pm 3.42$ \\
7.8 & $95.4 \pm 0.8$ & $0.144 \pm 0.052$ & $8.98 \pm 0.39$ & $92.09 \pm 0.190$
\end{tabular}

Notes: Mean \pm standard deviation, $n=3$; -, not measured.

Abbreviations: BSA, bovine serum albumin; DEE, drug encapsulation efficiency: DLE, drug loading efficiency; DLS, dynamic light scattering; DOX, doxorubicin; $\mathrm{DOX} \cdot \mathrm{HCl}$, doxorubicin hydrochloride; NPs, nanoparticles; PDI, polydispersity index; $V$, vanillin; $w$, weight.

interaction between DOX and BSA-V-NPs was enhanced and as a result, the BSA-V-NPs possessed a higher DLE and a more compact structure (Table 1). ${ }^{24}$ However, as the amount of $\mathrm{DOX} \cdot \mathrm{HCl}$ was fixed, when all the DOX molecules in the system were unprotonated, the DLE and DEE would be relatively constant. Herein, a $\mathrm{pH}$ of 7.4 was chosen in the following study due to the satisfactory encapsulation efficiency and drug loading.

The influence of BSA/DOX $\mathrm{HCl}$ ratio $(\mathrm{w} / \mathrm{w})$ on the formation of DOX-BSA-V-NPs was also studied. As the $\mathrm{BSA} / \mathrm{DOX} \cdot \mathrm{HCl}$ ratio decreased, the particle size and DLE increased, while the DEE decreased (Table 2). Compared with the DOX-BSA-Dextran-NPs reported by Deng et al, ${ }^{24}$ the DOX-BSA-V-NPs possessed a similar DLE and DEE at the same BSA/DOX $\cdot \mathrm{HCl}$ ratio, but a slightly larger size. For the sake of investigating the in vivo behavior, a $\mathrm{BSA} / \mathrm{DOX} \cdot \mathrm{HCl}$ ratio of $10: 1$, a comparable size as the DOX-BSA-NPs (vanillin free), was selected. The zeta potential of the resultant NPs was $-23.05 \pm 1.45 \mathrm{mV}$.

\section{Characterization of DOX-BSA-V-NPs}

The morphology of the NPs was observed by the TEM. As shown in Figure 1, both the DOX-free NPs and DOX-BSA-V-NPs were spherical or ellipsoidal with a diameter $\sim 80-90 \mathrm{~nm}$.

Table 2 DLS, DLE, and DEE results of DOX-BSA-V-NPs prepared at different BSA/DOX. $\mathrm{HCl}$ ratios $(\mathrm{w} / \mathrm{w})$

\begin{tabular}{lllll}
\hline $\begin{array}{l}\text { BSA/DOX.HCl } \\
\text { (w/w) }\end{array}$ & $\begin{array}{l}\text { Particle size } \\
(\mathbf{n m})\end{array}$ & PDI & DLE (\%) & DEE (\%) \\
\hline $20: 1$ & $100.1 \pm 0.7$ & $0.139 \pm 0.042$ & $4.28 \pm 0.23$ & $89.07 \pm 5.07$ \\
$10: 1$ & $100.5 \pm 1.3$ & $0.122 \pm 0.022$ & $8.29 \pm 0.049$ & $85.45 \pm 6.38$ \\
$5: 1$ & $134.6 \pm 4.2$ & $0.150 \pm 0.048$ & $13.98 \pm 0.24$ & $77.94 \pm 1.58$ \\
2:1 & $189.6 \pm 5.7$ & $0.245 \pm 0.029$ & $27.77 \pm 0.50$ & $73.89 \pm 1.86$ \\
\hline
\end{tabular}

Note: Mean \pm standard deviation, $n=3$.

Abbreviations: BSA, bovine serum albumin; DEE, drug encapsulation efficiency; DLE, drug loading efficiency; DLS, dynamic light scattering; DOX, doxorubicin; DOX.HCl, doxorubicin hydrochloride; NPs, nanoparticles; PDI, polydispersity index; $\mathrm{V}$, vanillin; $\mathrm{w}$, weight. 

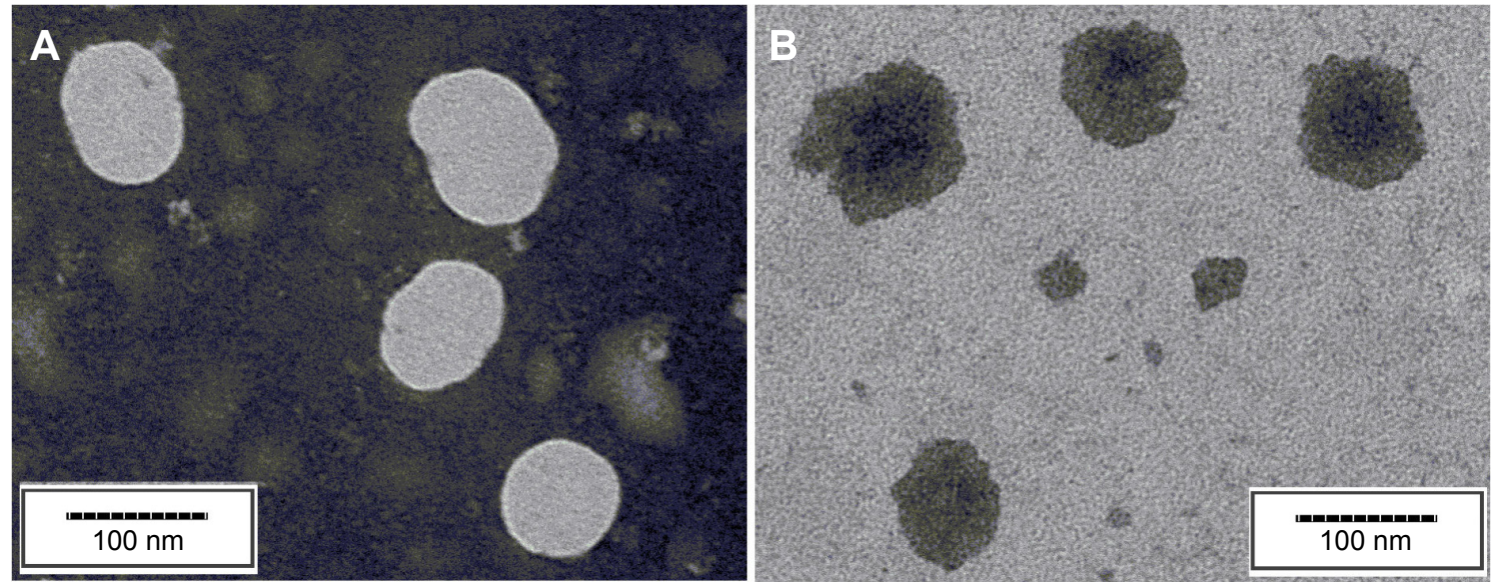

Figure I TEM images of the nanoparticles.

Notes: (A) BSA-V-NPs, scale bar $100 \mathrm{~nm}$; (B) DOX-BSA-V-NPs, scale bar $100 \mathrm{~nm}$.

Abbreviations: BSA, bovine serum albumin; DOX, doxorubicin; NPs, nanoparticles; TEM, transmission electron microscopy; $V$, vanillin.

Compared with the DLS data, the particle size of TEM was smaller, since the TEM captured the images of the dried NPs, whereas the DLS determined the hydrodynamic diameter. ${ }^{24}$

The conformational changes of BSA were observed by the CD spectra. As shown in Figure 2, the spectra of both DOX-loaded and DOX-free BSA-V-NPs exhibited two negative peaks $\sim 210$ and $220 \mathrm{~nm}$, which were the characteristic bands of the $\alpha$-helix structure. ${ }^{30}$ As the amount of DOX increased, the $\mathrm{CD}$ intensities increased remarkably, indicating that the structure of BSA became highly ordered. The calculated results of the $\alpha$-helical content of BSA showed

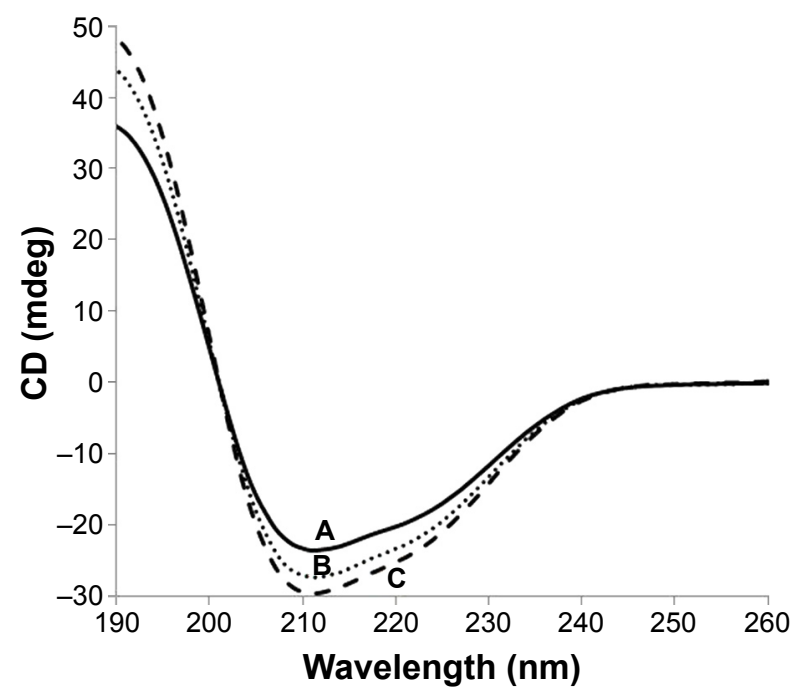

Figure 2 CD spectra of BSA-V-NPs and DOX-BSA-V-NPs.

Notes: (A) BSA-V-NPs (0\% DOX); (B) DOX-BSA-V-NPs (2.5\% DOX); and (C) DOX-BSA-V-NPs (5\% DOX).

Abbreviations: BSA, bovine serum albumin; $C D$, circular dichroism; DOX, doxorubicin; NPs, nanoparticles; $V$, vanillin. that the $\alpha$-helix structure increased from $28.2 \%(0 \%$ DOX) to $28.4 \%(2.5 \% \mathrm{DOX})$ and $30.2 \%(5 \% \mathrm{DOX})$. These findings suggested that the interaction between DOX and BSA-V-NPs enhanced as the additional amount of DOX increased.

The physical status of DOX inside the BSA-V-NPs was investigated using DSC. As shown in Figure 3B, the melting endothermic peaks of DOX were found between $200^{\circ} \mathrm{C}$ and $240^{\circ} \mathrm{C}$. The DSC thermogram of DOX-BSA-V-NPs (Figure 3C) was similar to that of BSA-V-NPs (Figure 3D), while the thermogram of the physical mixture (Figure 3A) showed all the endothermic peaks of DOX and BSA-V-NPs, indicating the successful encapsulation of DOX into the BSA-V-NPs.

To provide additional evidence, Raman spectroscopy was also used to examine the encapsulation of DOX into the NPs. The Raman spectrum of DOX (Figure 4A) showed two strong peaks at 1,648 (e) and $1,290 \mathrm{~cm}^{-1}(\mathrm{~g})$ corresponding to the amido bands, $\mathrm{C}=\mathrm{O}$ and $\mathrm{C}-\mathrm{N}$ stretching vibrations, a strong peak attributing to $\mathrm{C}-\mathrm{N}$ stretching vibrations at $1,425 \mathrm{~cm}^{-1}$ (f) and a peak at $790 \mathrm{~cm}^{-1}$ (h) corresponding to the bending vibrations in substituted phenyl rings. The Raman spectrum of the BSA-V-NPs (Figure 4B) contained a strong peak corresponding to the protein band between 2,910 and 2,970 $\mathrm{cm}^{-1}$ (a), a strong broad peak at $1,657 \mathrm{~cm}^{-1}$ attributed to the $\mathrm{C}=\mathrm{O}$ stretching vibrations (b), a strong peak at $1,450 \mathrm{~cm}^{-1}$ due to the $\mathrm{CH}_{2}$ bending vibrations (c) and a prominent peak at $1,000 \mathrm{~cm}^{-1}$ related to the ring stretching in the substituted phenyl rings (d). ${ }^{31}$ The Raman spectrum of DOX-BSA-V-NPs (Figure 4C) was similar to that of BSA-V-NPs (Figure 4B), but the Raman spectrum of the mixture of DOX and BSA-V-NPs (Figure 4D) showed all 


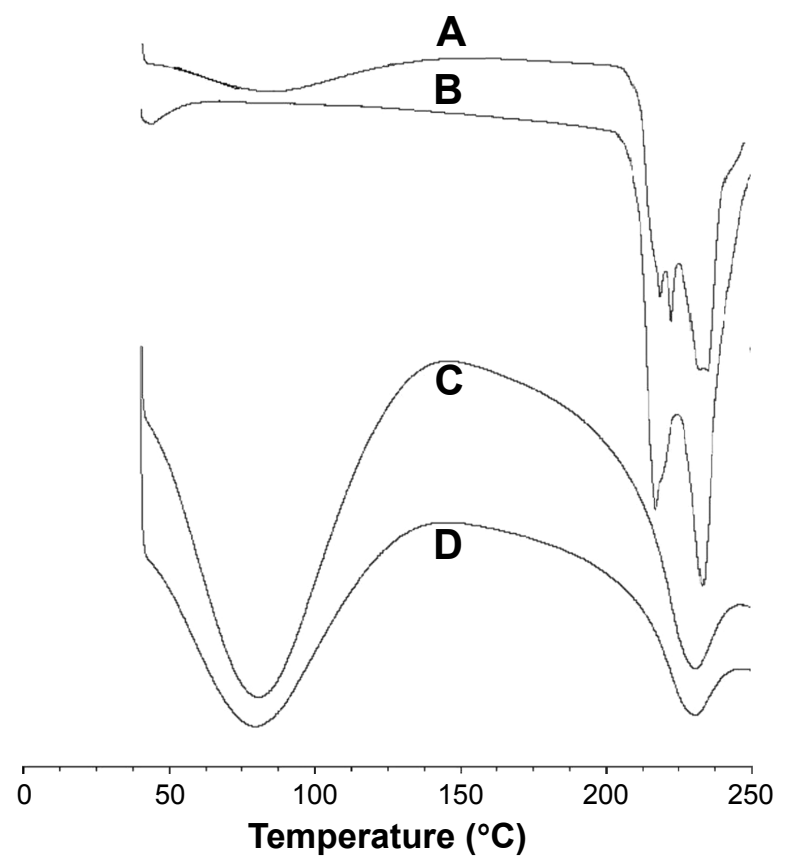

Figure 3 DSC curves.

Notes: Differential scanning calorimetric thermograms of $(\mathbf{A})$ mixture of DOX and BSA-V-NPs, (B) DOX, (C) DOX-BSA-V-NPs, and (D) BSA-V-NPs.

Abbreviations: BSA, bovine serum albumin; DOX, doxorubicin; NPs, nanoparticles; $\mathrm{V}$, vanillin; DSC, differential scanning calorimetric.

the peaks in Figure 4A and 4B, confirming that the DOX was encapsulated into the BSA-V-NPs.

\section{Stability of DOX-BSA-V-NPs}

The kinetic stability of DOX-BSA-V-NPs was determined by DLS. The time-dependent changes in the size of the NPs in $0.9 \% \mathrm{NaCl}$ and $5 \%$ glucose solutions at $37^{\circ} \mathrm{C}$ are shown in Figure 5A, while the diameter changes of 10 days storage at $40^{\circ} \mathrm{C}$ and 2 months storage at $4^{\circ} \mathrm{C}$ are shown in Figure 5B. The mean particle size of DOX-BSA-V-NPs remained constant for 48 hours at $37^{\circ} \mathrm{C}$ in $0.9 \% \mathrm{NaCl}$ (Figure $5 \mathrm{~A}, 1$ ) and $5 \%$ glucose (Figure 5A,2). Moreover, the size of the NPs hardly changed even after 10 days storage at $40^{\circ} \mathrm{C}$ (Figure 5B,1) and 60 days storage at $4^{\circ} \mathrm{C}$ (Figure $\left.5 \mathrm{~B}, 2\right)$. These results indicated that the DOX-BSA-V-NPs were kinetically stable and suitable for in vivo application.

\section{Doxorubicin release in vitro}

The release profile of DOX from the DOX-BSA-V-NPs in PBS buffer (pH 7.4 and $\mathrm{pH} 6.5$ ), $10 \mu \mathrm{M} \mathrm{GSH}$ (pH 7.4), and $20 \mathrm{mM} \mathrm{GSH}(\mathrm{pH} 6.5)$ at $37^{\circ} \mathrm{C}$ are shown in Figure 6 with the free DOX as a control. The results showed that the diffusion of the DOX solution was fast with $100 \%$ accumulative release after 6,8 , and 12 hours, respectively, whereas the NPs exhibited a sustained release due to the compact BSA network and the interaction between DOX and NPs. To evaluate the release kinetics of DOX from the formulations, in vitro release data were fitted to different mathematical equations including zero order, first order, Higuchi, and Weibull using the software of DDSolver. ${ }^{32}$ Each release pattern fit the Weibull equation and the parameters are listed in Table 3. Because of the comparatively higher solubility of protonated DOX and weaker interactions between DOX and NPs at lower $\mathrm{pH}$ values, both the free DOX and DOX-BSA-V-NPs showed faster diffusion/release in $\mathrm{pH} 6.5$ buffers than in 7.4 buffers. ${ }^{22,24}$ Moreover, the NPs showed quicker and greater release in greater concentration GSH solutions $(20 \mathrm{mM})$ than in lower GSH concentration

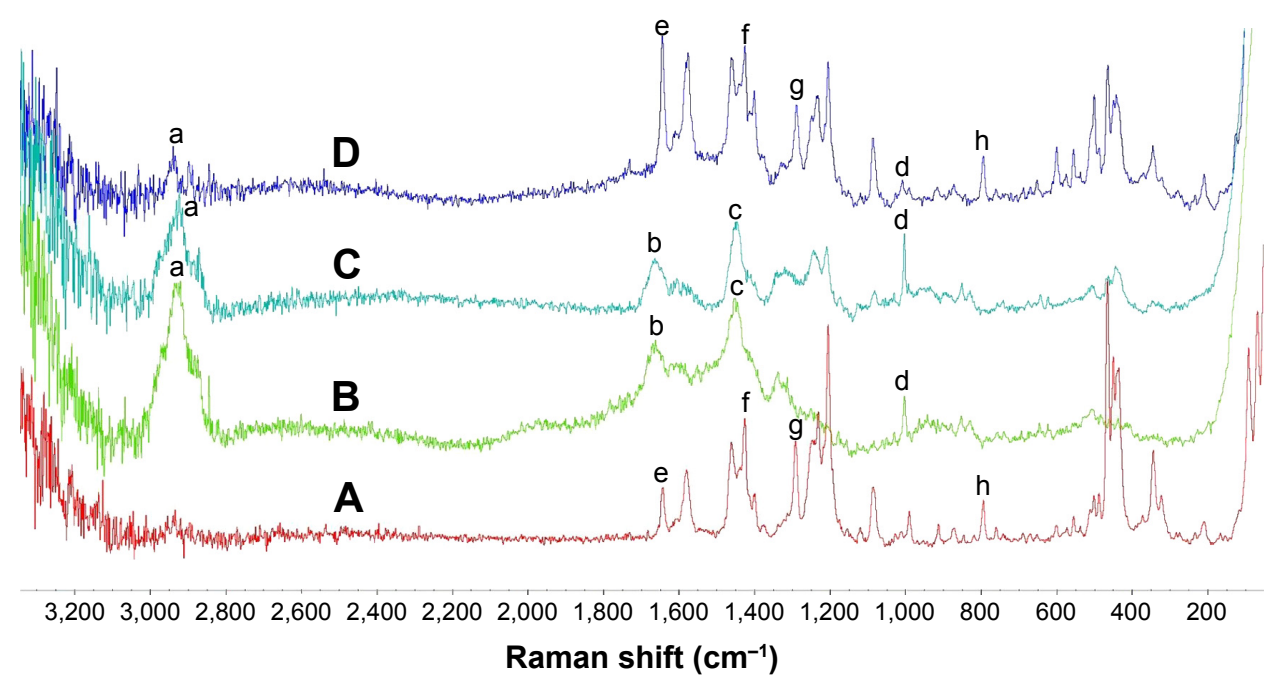

Figure 4 Raman spectra of (A) DOX, (B) BSA-V-NPs, (C) DOX-BSA-V-NPs, and (D) mixture of DOX and BSA-V-NPs.

Notes: a, protein band; $b, \mathrm{C}=\mathrm{O}$ stretching vibrations; $\mathrm{c}, \mathrm{CH} 2$ bending vibrations; $\mathrm{d}$, ring stretching in the substituted phenyl rings; e and $\mathrm{g}$, amido bands, $\mathrm{C}=\mathrm{O}$ and $\mathrm{C}-\mathrm{N}$ stretching vibrations; $\mathrm{f}, \mathrm{C}-\mathrm{N}$ stretching vibrations; $\mathrm{h}$, bending vibrations in substituted phenyl rings. Abbreviations: BSA, bovine serum albumin; DOX, doxorubicin; NPs, nanoparticles; V, vanillin. 

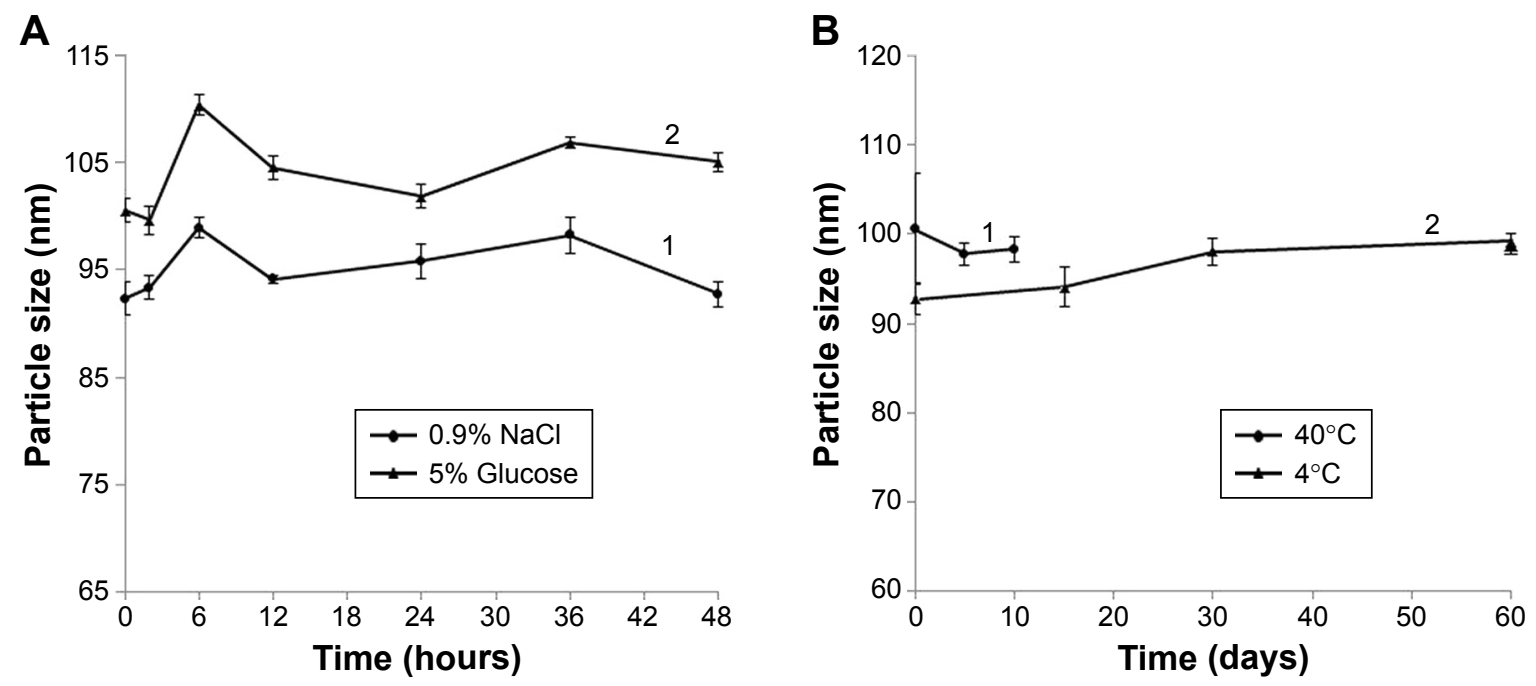

Figure 5 Stability of DOX-BSA-V-NPs in different conditions.

Notes: $(\mathbf{A}, \mathbf{I}) 0.9 \% \mathrm{NaCl}$ solution; $(\mathbf{A}, 2) 5 \%$ glucose solution; $(\mathbf{B}, \mathbf{I}) 10$ days at $40^{\circ} \mathrm{C} ;(\mathbf{B}, 2) 60$ days at $4^{\circ} \mathrm{C}$.

Abbreviations: BSA, bovine serum albumin; DOX, doxorubicin; NPs, nanoparticles; V, vanillin.

solutions $(10 \mu \mathrm{M})$ due to the presence of a large number of disulfide bridges in the NPs. In addition, the release curve of DOX-BSA-V-NPs in PBS buffer (pH 7.4) was similar to that in $10 \mu \mathrm{M}$ GSH ( $\mathrm{pH} 7.4$ ), suggesting that the appearance of lower GSH concentrations did not significantly affect the

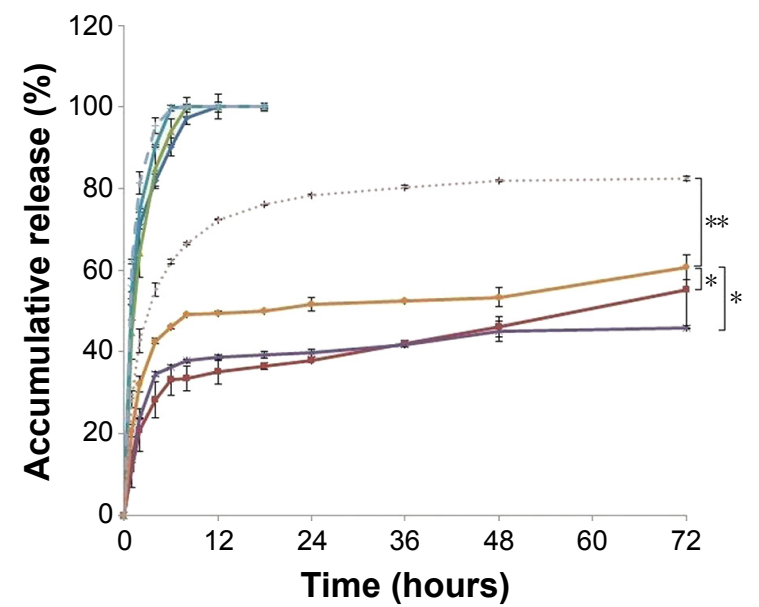

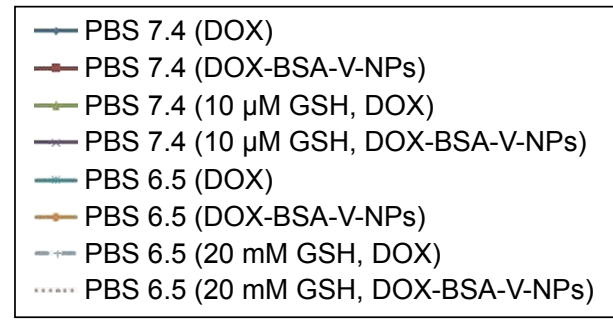

Figure 6 Accumulative release of DOX from DOX-BSA-V-NPs in PBS buffer ( $\mathrm{pH} 7.4$ and $\mathrm{pH} 6.5), 10 \mu \mathrm{M} \mathrm{GSH}(\mathrm{pH} 7.4)$, and $20 \mathrm{mM} \mathrm{GSH}(\mathrm{pH} 6.5)$ with the free DOX as a control. $* P<0.05$ and $* * P<0.01$.

Abbreviations: BSA, bovine serum albumin; DOX, doxorubicin; GSH, glutathione; NPs, nanoparticles; PBS, phosphate-buffered saline; $V$, vanillin. release behavior. As $10 \mu \mathrm{M}$ GSH (pH 7.4) and $20 \mathrm{mM}$ GSH (pH 6.5) were separately used to simulate the physiological condition of the blood and tumor cells, the $\mathrm{pH}-$ and GSHsensitive release profiles of the NPs might be beneficial to increase their stability in the circulatory system and enhance DOX release in the tumor cells. ${ }^{33,34}$

\section{Cellular uptake and uptake mechanism}

The internalization of drugs into the cancer cells is a prerequisite for their anticancer effects. As shown in Figure 7, both the intracellular uptake of free DOX and DOX-BSAV-NPs by BGC-823 cells showed a concentration- and time-dependent manner. The fluorescence of the cells treated with the formulations with a DOX concentration of $6.24 \mu \mathrm{g} / \mathrm{mL}$ was stronger than $0.78 \mu \mathrm{g} / \mathrm{mL}$ (Figure $7 \mathrm{~A}, \mathrm{C}$, and $\mathrm{E}$ ), while that of 8 hours was stronger than 0.5 hours (Figure 7B, D, and F). Moreover, the CLSM images (Figure 7G) also demonstrated that the uptake of DOX-BSAV-NPs was more efficient than that of free DOX at $37^{\circ} \mathrm{C}$ for 4 hours, indicating that the BSA-V-NPs enhanced the cellular uptake of DOX.

Understanding the intracellular fate of NPs is crucial for drug design due to its importance in drug delivery and release. As shown in Figure 8A, the internalization of RBITC-labeled BSA-V-NPs in BGC-823 cells was clearly observed (Figure 8A,2), while the nuclei and endo-lysosomes were separately stained in blue (Figure 8A,1) and green (Figure 8A,3). Colocalization between the signal of RBITClabeled BSA-V-NPs and the signal of fluorochrome labeled 
Table 3 Weibull parameters for DOX release data modeling

\begin{tabular}{|c|c|c|c|}
\hline Formulation & Release medium & Fitting equation & $r$ \\
\hline \multirow[t]{4}{*}{ Free DOX } & PBS (pH 7.4) & $F=1-e-0.7 \mid 5(t+0.037) 0.693$ & 0.9955 \\
\hline & PBS (pH 6.5) & $F=|-e-0.29|(t+1.190) \mid .317$ & 0.9983 \\
\hline & $10 \mu \mathrm{M}$ GSH (pH 7.4) & $F=|-e-0.278(t+0.874)| .225$ & 0.9994 \\
\hline & 20 mM GSH (pH 6.5) & $F=|-e-0.569(t+0.606)| .125$ & 0.9998 \\
\hline \multirow[t]{4}{*}{ DOX-BSA-V-NPs } & PBS (pH 7.4) & $F=1-e-0.237(t-0.929) 0.255$ & 0.9799 \\
\hline & PBS (pH 6.5) & $F=I-e-0.450(t-0.986) 0.158$ & 0.9749 \\
\hline & I0 $\mu \mathrm{M}$ GSH (pH 7.4) & $F=|-e-0.33|(t-0.995) 0.150$ & 0.9782 \\
\hline & $20 \mathrm{mM}$ GSH $(\mathrm{pH} 6.5)$ & $F=I-e-0.598(t-0.878) 0.285$ & 0.9919 \\
\hline
\end{tabular}

Abbreviations: BSA, bovine serum albumin; DOX, doxorubicin; F, drug released fraction at time $t$; GSH, glutathione; NPs, nanoparticles; PBS, phosphate-buffered saline; $r$, correlation coefficient; $t$, release time; $\mathrm{V}$, vanillin.

cells was investigated by CLSM. As shown in Figure 8A,4, a lot of yellow or orange dots appeared in the overlapped images after incubation with RBITC-labeled BSA-V-NPs for 4 hours, suggesting that the BSA-V-NPs were mainly located in the endo-lysosomes following endocytosis. As shown in Figure $8 \mathrm{~B}$, none of the inhibitors affected the uptake of free DOX. However, the cellular uptake of DOX-BSA-V-NPs was remarkably decreased by pretreatment with sucrose, indicating that clathrin-mediated endocytosis was the main uptake pathway of the NPs. These findings were consistent with the results of the endo-lysosome labeling experiment. In addition, the CLSM images also showed that DOX accumulated in the nuclei (Figure 7G) although the BSA-V-NPs were entrapped in the endo-lysosomes after cellular uptake (Figure 8A), confirming the endo-lysosomal escape capability of the BSA-V-NPs.

\section{Cytotoxicity assay}

Cytotoxicity studies suggested that free DOX and DOX-BSAV-NPs inhibited proliferation of BGC-823 cells in a dosedependent manner (Figure 9). Compared with free DOX, the cell inhibition rate of DOX-BSA-V-NPs was slightly higher and the $\mathrm{IC}_{50}$ values calculated for DOX and DOX-BSA-VNPs were $4.007 \pm 0.378$ and $3.693 \pm 0.525 \mu \mathrm{g} / \mathrm{mL}$, respectively, after treatment for 48 hours, indicating that the NPs produced a stronger antitumor activity. This can be attributed to the sustained drug release pattern from DOX-BSA-V-NPs, as well as the higher cellular uptake of the NPs.

\section{Biodistribution examination in vivo}

To examine the in vivo distribution of the BSA-V-NPs, the lipophilic fluorescent dye DiR-labeled BSA-V-NPs were administrated to the xenograft Heps tumor-bearing mice via tail vein injection. The DiR signal was clearly observed at the tumor site at 4 hours postinjection, enhanced at 6 hours and remained up to 24 hours (Figure 10), indicating that the BSA-V-NPs have tumor targeting ability and can be retained in the tumors.

In order to quantitatively assess the in vivo distribution of the DOX formulations, the Heps tumor-bearing mice were sacrificed at various time points after administration of free DOX, DOX-BSA-NPs, and DOX-BSA-V-NPs. The concentration of DOX in the heart and tumor was determined by HPLC equipped with a fluorescence detector. The DOX concentrations for DOX-BSA-V-NPs and DOX-BSA-NPs in the tumors were 1.53-, 0.70-, 0.98-, and 1.52-fold as well as 1.36-, 0.40-, 0.58-, and 0.96-fold higher than that of free DOX after 6, 12, 24, and 48 hours, respectively. However, there was no significant difference between the two NP groups. On the contrary, the DOX concentration for free DOX in the heart was significantly higher than that of the DOX NPs. Hence, compared with free DOX, the NP formulations showed enhanced tumor accumulation and decreased heart distribution (Figure 11), indicating that BSA-NPs could improve the biodistribution of DOX and the cardiac toxicity could be greatly reduced as a result. The constant concentration of DOX in the tumor from 12 to 48 hours postinjection indicated that the NPs could be retained in the tumor for a long time period. This finding was consistent with the NIRF observation.

\section{In vivo antitumor efficacy}

To investigate the antitumor effect of DOX NPs, the survival study in Heps tumor-bearing mice was undertaken. The detailed data of mean survival time are shown in Figure 12 and the calculated parameters are presented in Table 4 . The mean survival time and lifespan of tumor-bearing mice were significantly prolonged by the NPs, whereas the free DOX had no obvious effect (Table 4). The result indicated that the NPs were more effective than free DOX to increase the lifespan of the tumor-bearing 
A

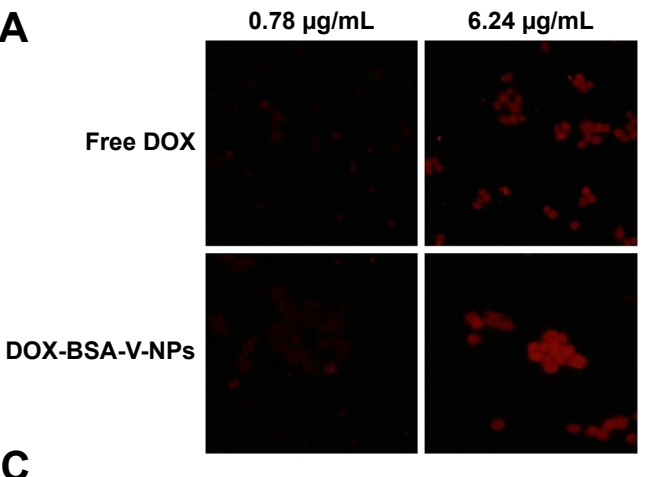

C

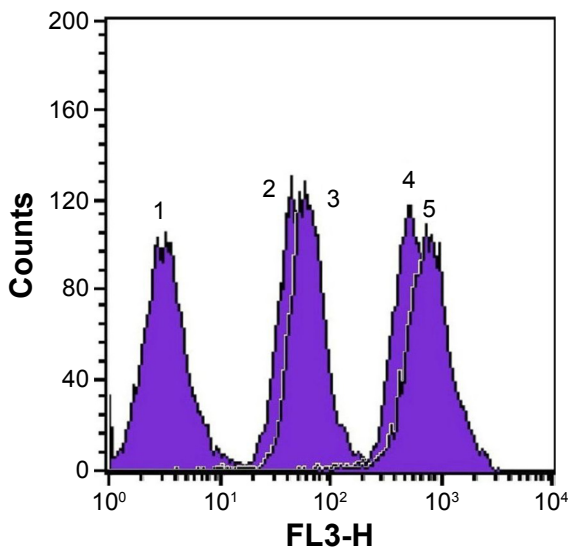

E

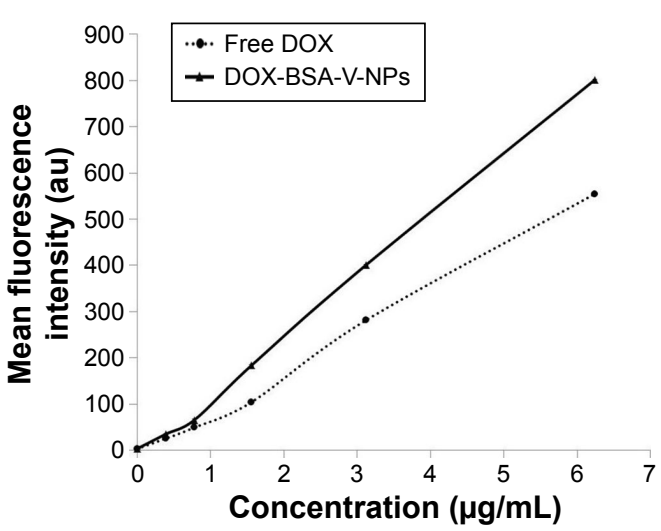

G

DOX
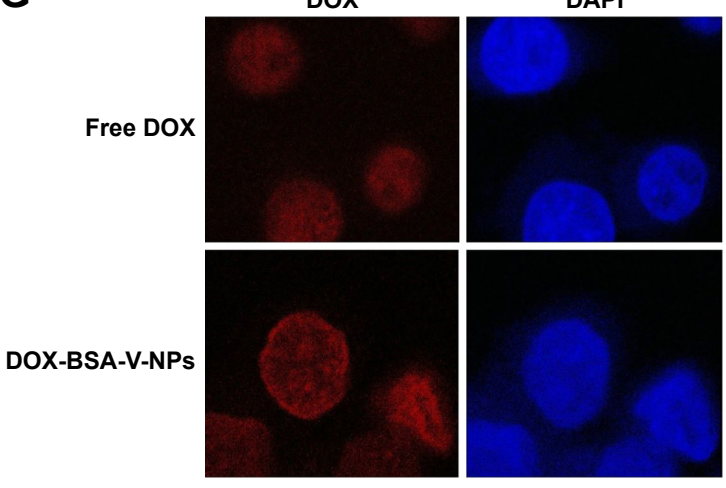

B

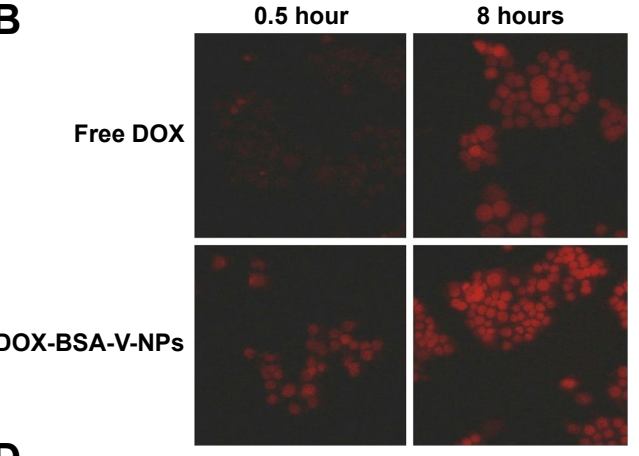

D

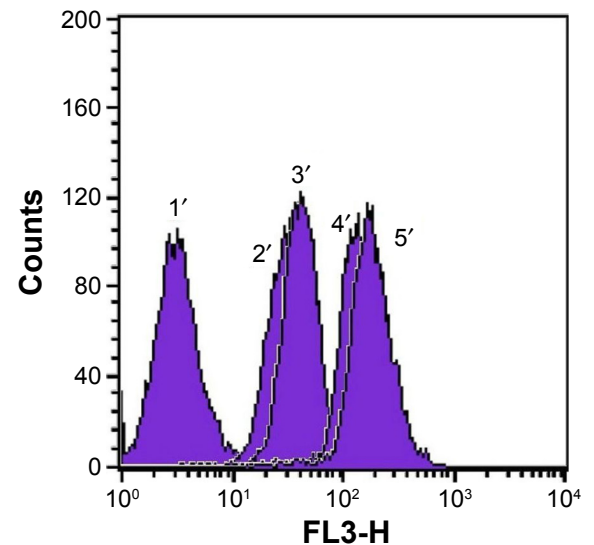

$\mathbf{F}$

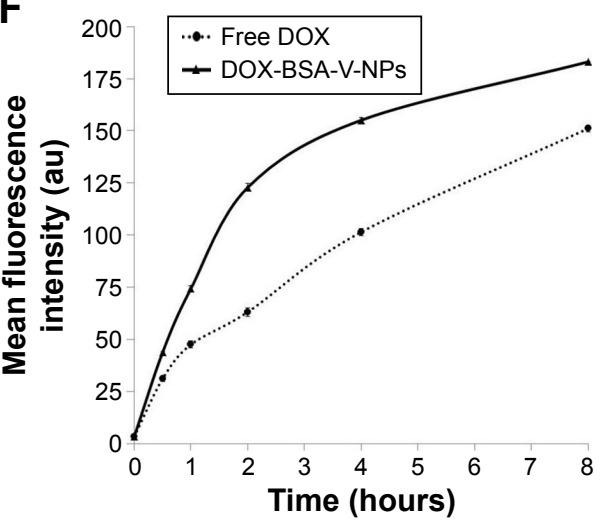

Bright
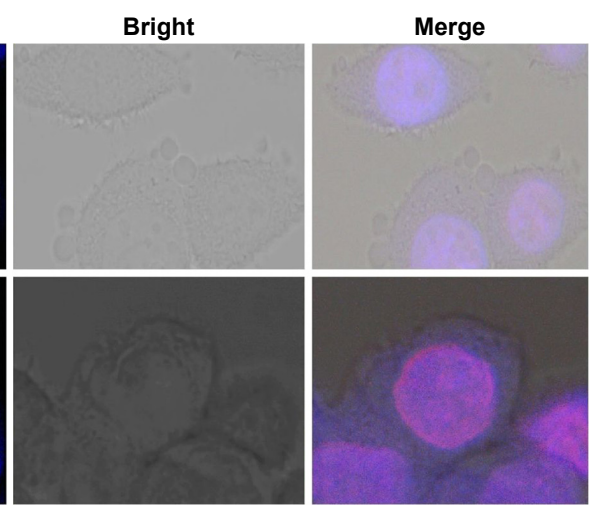

Figure 7 Cellular uptake of free DOX and DOX-BSA-V-NPs.

Notes: Cellular internalization of free DOX and DOX-BSA-V-NPs observed by (A, B) inverted fluorescence microscopy (100x magnification), (C-F) flow cytometry, and (G) CLSM (400X magnification). (C) I, control; 2, free DOX (0.78 $\mu \mathrm{g} / \mathrm{mL}$, 2 hours); 3, DOX-BSA-V-NPs ( $0.78 \mu \mathrm{g} / \mathrm{mL}$, 2 hours); 4 , free DOX (6.24 $\mu \mathrm{g} / \mathrm{mL}$, 2 hours); 5 , DOX-

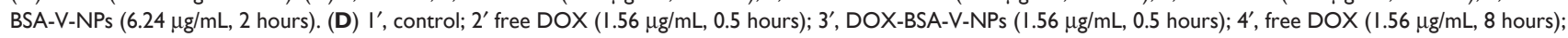
5', DOX-BSA-V-NPs (1.56 $\mu \mathrm{g} / \mathrm{mL}, 8$ hours). (E) Concentration-dependent uptake of free DOX and DOX-BSA-V-NPs. The cells were exposed to various concentrations of the DOX formulations at $37^{\circ} \mathrm{C}$ for 4 hours, and subsequently determined by flow cytometry. (F) Time-dependent uptake of free DOX and DOX-BSA-V-NPs. The cells were treated with the DOX formulations at a concentration of $1.56 \mu \mathrm{g} / \mathrm{mL}$ at $37^{\circ} \mathrm{C}$ and then analyzed by flow cytometry. (G) DOX (I.56 $\mu \mathrm{g} / \mathrm{mL}, 4$ hours) and DOX-BSA-V-NPs ( $1.56 \mu \mathrm{g} / \mathrm{mL}, 4$ hours).

Abbreviations: BSA, bovine serum albumin; CLSM, confocal laser scanning microscopy; DAPI, 4',6-diamidino-2-phenylindole; DOX, doxorubicin; NPs, nanoparticles; V, vanillin. 
A
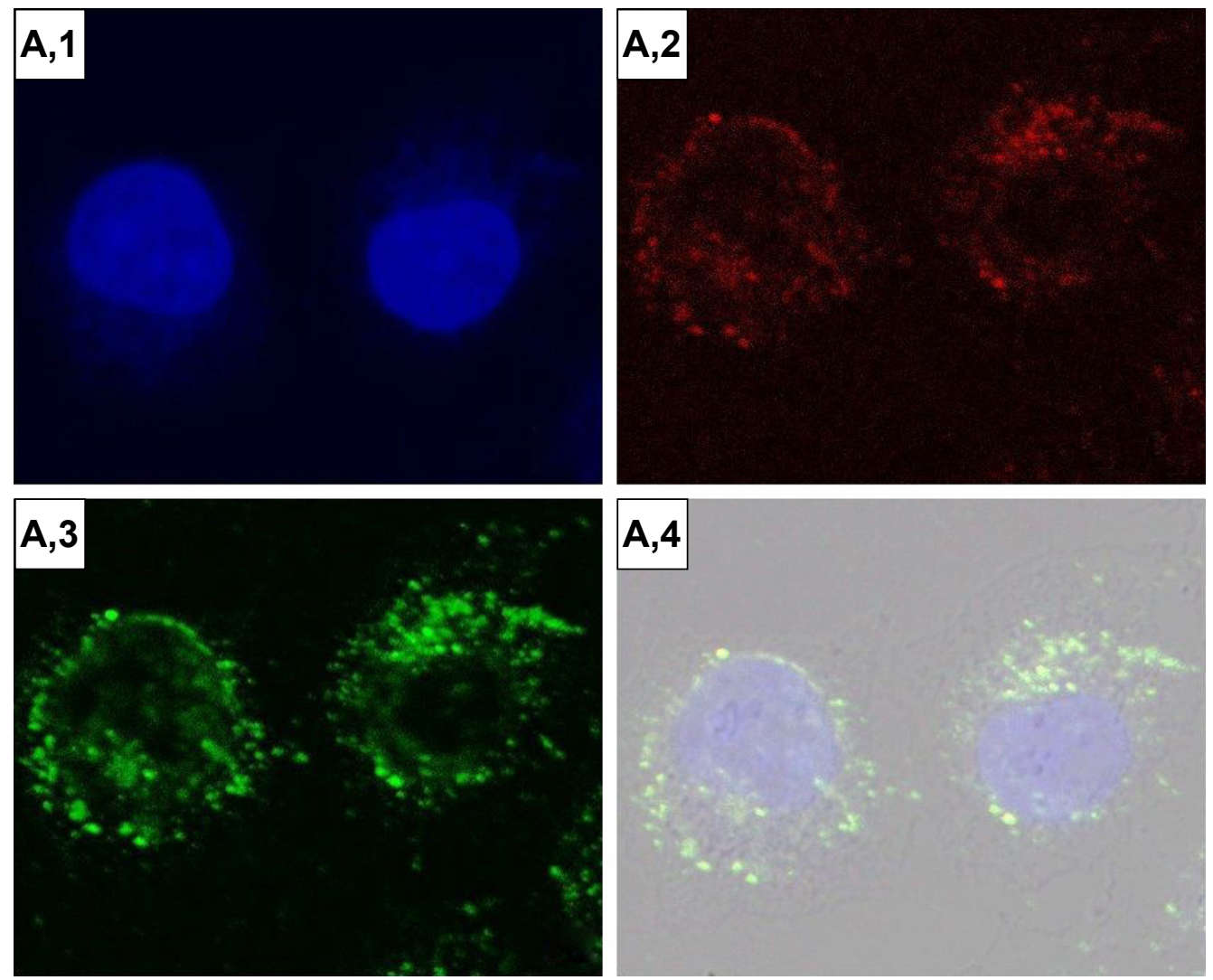

B
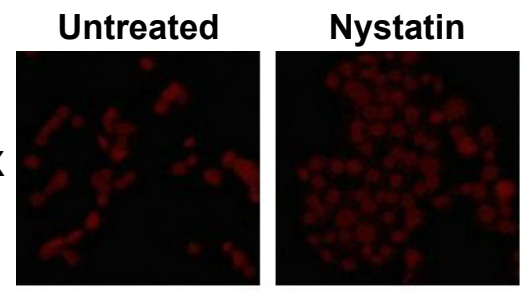

\section{Sucrose}

Free DOX

DOX-BSA-V-NPs
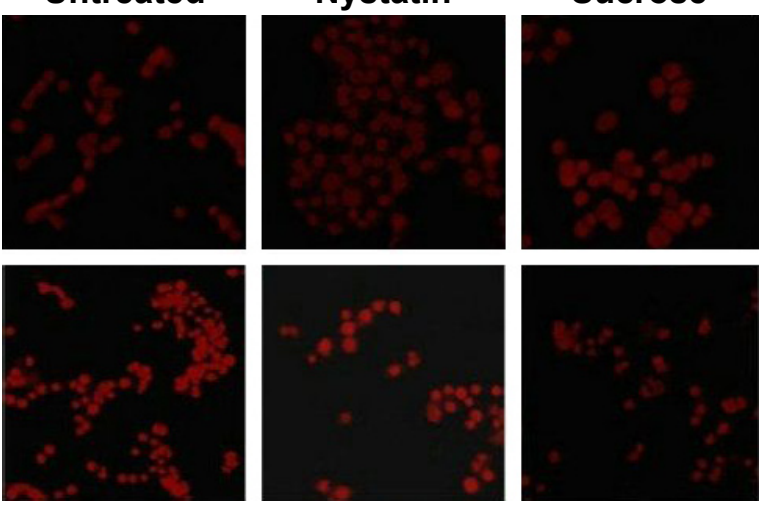

Figure 8 Cellular uptake mechanism investigated by (A) CLSM and (B) inverted fluorescence microscopy.

Notes: Uptake pathways of DOX-BSA-V-NPs in BGC-823 cells studied by using (A) LysoTracker Green (400× magnification) and (B) endocytic inhibitors (I00× magnification). (A, I) DAPI; (A,2) RBITC-labeled BSA-V-NPs; (A,3) LysoTracker Green; (A,4) merge.

Abbreviations: BSA, bovine serum albumin; CLSM, confocal laser scanning microscopy; DAPI, 4',6-diamidino-2-phenylindole; DOX, doxorubicin; RBITC, rhodamin B isothiocyanate; NPs, nanoparticles; V, vanillin.

mice. In addition, the group treated with DOX-BSA-V-NPs had the longest mean survival time and the biggest survivability rate, and there were significant differences between the DOXBSA-V-NPs group and other groups (the $P$-values calculated by one-tailed $t$-tests are shown in Table S1).

To further evaluate the antitumor effect of the DOX NPs, a tumor suppression experiment was performed using the Heps tumor-bearing mice. The tumor volume and tumor inhibition rate of different treatments were exhibited in
Table 5. The tumor volume of the DOX formulations was smaller than that of normal saline, indicating that DOX could inhibit tumor growth. Compared with free DOX, the tumor volume of the NPs was even smaller, suggesting that the tumor suppression of DOX-loaded NPs was more potent. Moreover, no significant difference between the two NP groups was found in this study.

The hearts and tumors were washed, fixed in $10 \%$ formalin, embedded in paraffin blocks, sliced into $5 \mathrm{~mm}$ thick 


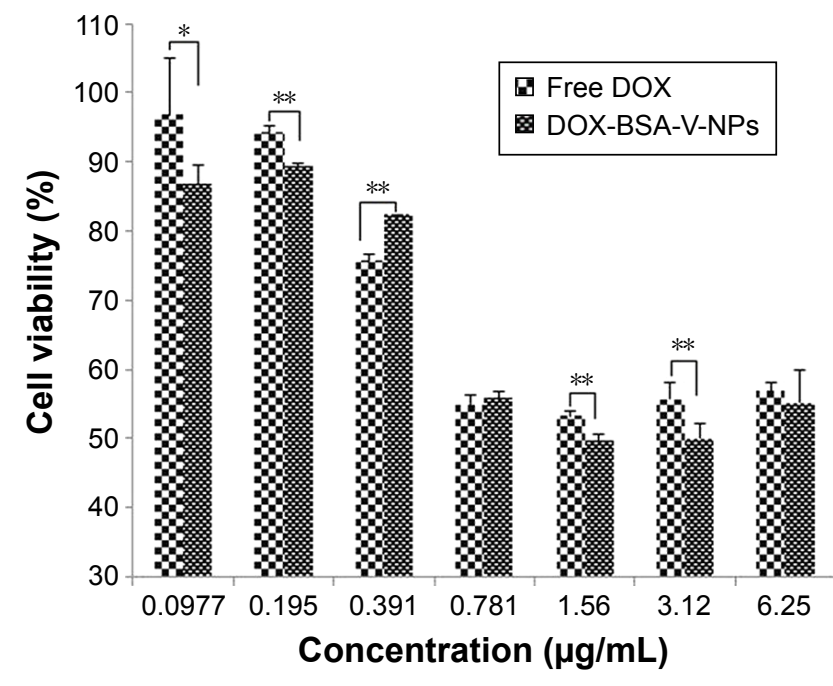

Figure 9 In vitro cytotoxicity of DOX and DOX-BSA-V-NPs against BGC-823 cells for 48 hours of treatment assessed by using the CCK-8 assay. $* P<0.05$, $* * P<0.01$. Abbreviations: BSA, bovine serum albumin; DOX, doxorubicin; NPs, nanoparticles; $\mathrm{V}$, vanillin.

sections, and placed onto glass slides. ${ }^{35,36}$ After staining with HE for microscopic observation, the images of pathology analysis are displayed in Figure 13. In a normal saline group, myocardial fibers arranged neatly (Figure 13A,1), while a slight extension of the myocardial fiber gap was observed in the NP groups (Figure 13A,3 and 13A,4, black arrow) and moderate focal edema necrosis (Figure 13A,2, black arrow) and focal band fibrosis (Figure 13A,2, red arrow) were noticed in the free DOX group. Moreover, the tumors exhibited typical pathological features in the control group, including closely packed, ${ }^{36}$ rich cytoplasm, large irregular karyons, and more nuclear division, ${ }^{37}$ while inflammatory infiltration (Figure 13B,2, red arrow) and cell apoptosis and spotty necrosis (Figure 13B,2, 13B,3, and 13B,4, black arrow) were observed in the tumor section of the DOX groups. The results presented evidence of the effective antitumor effect of the DOX formulations in vivo. In particular, compared with free DOX and DOX-BSA-NPs groups, the tumor tissues treated with DOX-BSA-V-NPs had the largest necrotic area. Hence, the results from histopathology analysis was in good accordance with other in vitro and in vivo findings and proved again the reduced side effects and enhanced antitumor activity of the NPs compared with free DOX. As the DOX distribution of the two NPs in tumor showed no significant difference, the greater in vivo antitumor effect of DOX-BSA-V-NPs than DOX-BSA-NPs in this study could be attributed to the existence of a Schiff base.

\section{Conclusion}

In this study, DOX was successfully loaded in Schiff base-based BSA-NPs with a diameter smaller than $200 \mathrm{~nm}$ and a high DLE of up to $27.77 \% \pm 0.50 \%$. In vitro studies indicated that the DOX-BSA-V-NPs could be quickly and effectively internalized in BGC-823 cells, mainly through clathrin-mediated endocytosis, and DOX accumulated in the nuclei after release from endo-lysosomes. The CCK-8 test demonstrated that the DOX-BSA-V-NPs had a relatively greater cytotoxicity than free DOX against BGC-823 cells. An in vivo distribution study indicated that the BSA-V-NPs possessed outstanding tumor targeting capacity and DOX could be delivered to the tumor. The DOX-BSA-V-NPs also showed superior extension of survival time than free DOX and DOX-BSA-NPs, and greater tumor suppression than free DOX. Besides, the cardiac toxicity of DOX was largely reduced by the NPs. All of these results indicated that tumor-targeted Schiff base-based BSA-NPs can be an effective drug carrier to enhance the anticancer effect of chemotherapy agents.

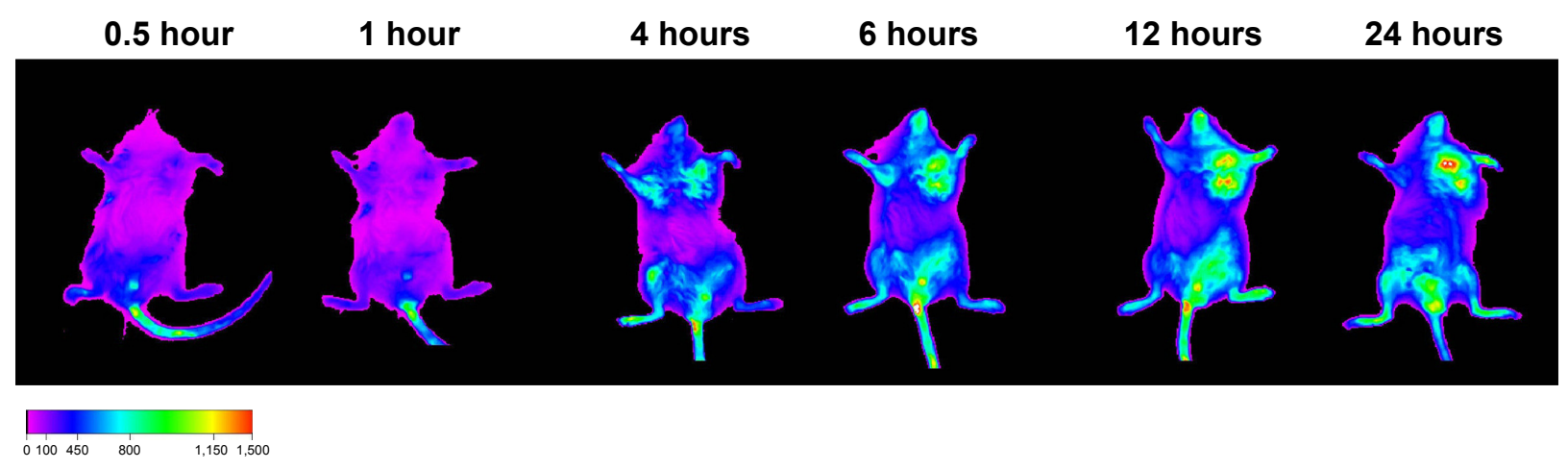

Figure 10 NIRF images of the xenograft Heps tumor-bearing mouse after intravenous injection of DiR-BSA-V-NPs.

Abbreviations: BSA, bovine serum albumin; DiR, I,I'-dioctadecyl-3,3,3',3'-tetramethylindotricarbocyanine iodide; DOX, doxorubicin; NIRF, near-infrared fluorescence; NPs, nanoparticles; $V$, vanillin. 
A

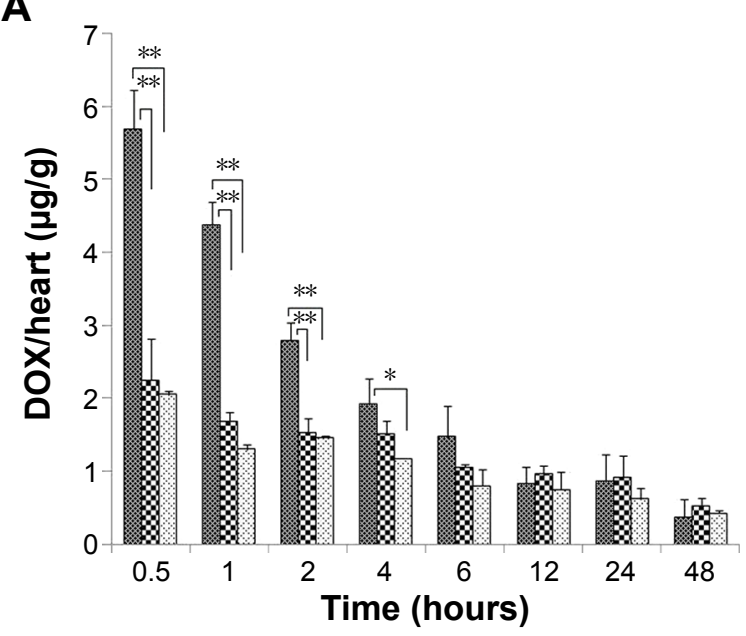

B

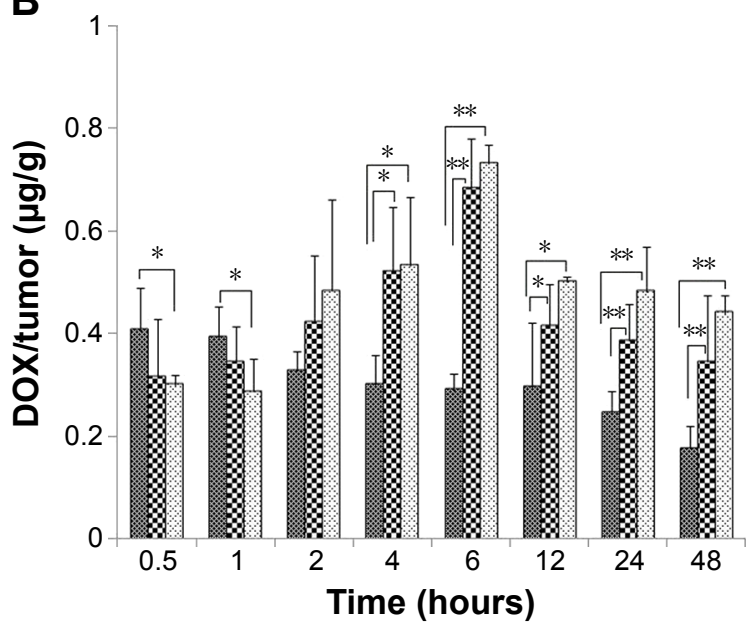

Free DOX DOX-BSA-NPs DOX-BSA-V-NPs

Figure II Biodistribution of free DOX, DOX-BSA-NPs and DOX-BSA-V-NPs in (A) heart and (B) tumor.

Notes: Time profiles of DOX accumulated in the $(\mathbf{A})$ heart and $(\mathbf{B})$ tumor after intravenous injection of different DOX formulations with a DOX dose of 5 mg kg ${ }^{-1}$. DOX/ heart and DOX/tumor are the ratios of the DOX amount in the heart $(\mu \mathrm{g})$ and tumor $(\mu \mathrm{g})$ to the tumor weight $(\mathrm{g})$, respectively. $* P<0.05$, $* * P<0.0 \mathrm{I}$.

Abbreviations: BSA, bovine serum albumin; DOX, doxorubicin; NPs, nanoparticles; V, vanillin.

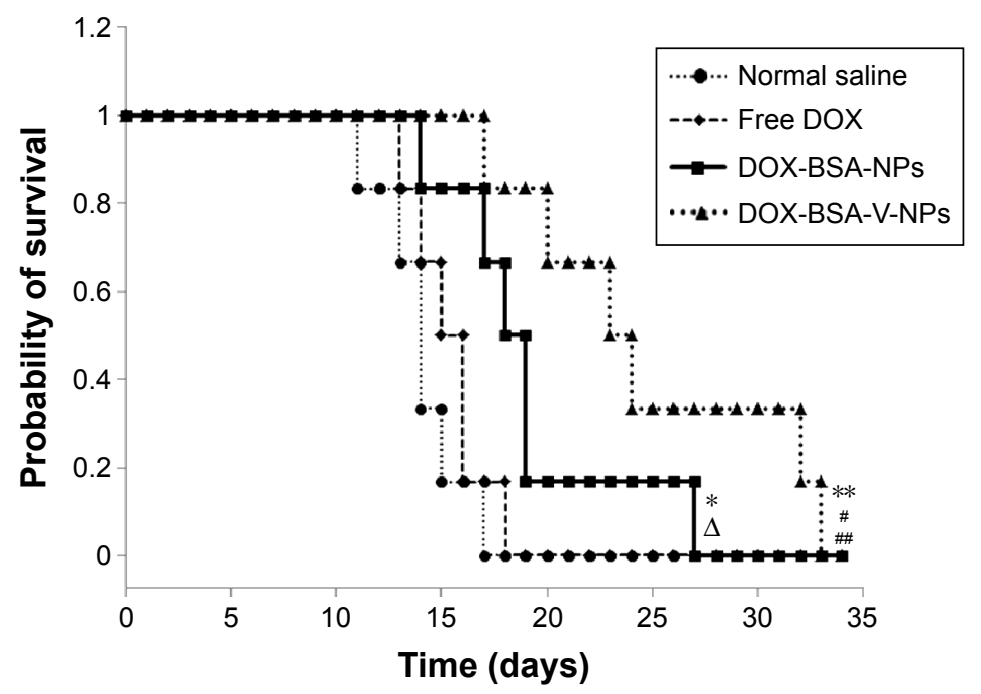

Figure 12 Survival curves of Heps tumor-bearing mice after administration with normal saline and different DOX formulations with a DOX dose of 5 mg. $\mathrm{kg}^{-1} \cdot$ day $^{-1}$ for 3 days. Notes: $* P<0.05$ vs normal saline group; ${ }^{*} P<0.05$ vs free $D O X$ group; ${ }^{* * P}<0.0$ I vs normal saline group; ${ }^{*} P<0.05$ vs $D O X-B S A-N P s$ group; ${ }^{*} P<0.0$ I vs free $D O X$ group.

Abbreviations: BSA, bovine serum albumin; DOX, doxorubicin; NPs, nanoparticles; $V$, vanillin.

Table 4 Survivability of Heps tumor-bearing mice after administration with normal saline and different DOX formulations with a DOX dose of $5 \mathrm{mg} \cdot \mathrm{kg}^{-1} \cdot$ day $^{-1}$ for 3 days

\begin{tabular}{lll}
\hline Group & $\begin{array}{l}\text { Mean survival time } \\
\text { (days) }\end{array}$ & Increase of lifespan (\%) \\
\hline Normal saline & $14.0 \pm 2.00$ & \\
Free DOX & $15.33 \pm 1.75$ & 9.52 \\
DOX-BSA-NPs & $19.0 \pm 4.34^{\mathrm{a}, \mathrm{b}}$ & 39.29 \\
DOX-BSA-V-NPs & $24.83 \pm 6.43^{\mathrm{c}, \mathrm{de}}$ & 57.14 \\
\hline
\end{tabular}

Notes: ${ }^{a}<<0.05$ compared with normal saline; ${ }^{b} P<0.05$ compared with free DOX; $c P<0.0$ I compared with normal saline; ${ }^{d} P<0.0$ I compared with free DOX; and e $P<0.05$ compared with DOX-BSA-NPs.

Abbreviations: BSA, bovine serum albumin; DOX, doxorubicin; NPs, nanoparticles; $\mathrm{V}$, vanillin.
Table 5 Tumor inhibition effects of normal saline and different DOX formulations on Heps tumor-bearing mice with a doxorubicin dose of $5 \mathrm{mg} \cdot \mathrm{kg}^{-1} \cdot$ day $^{-1}$ for 3 days

\begin{tabular}{lll}
\hline Group & Tumor volume $\left.\mathbf{( c m}^{3}\right)$ & $\begin{array}{l}\text { Tumor inhibition } \\
\text { rate (\%) }\end{array}$ \\
\hline Normal saline & $1.75 \pm 1.01$ & \\
Free DOX & $1.42 \pm 1.19$ & 19.2 \\
DOX-BSA-NPs & $0.772 \pm 0.370^{\mathrm{a}}$ & 55.94 \\
DOX-BSA-V-NPs & $0.760 \pm 0.466^{\mathrm{a}}$ & 56.66 \\
\hline
\end{tabular}

Note: ${ }^{a} P<0.05$ compared with normal saline.

Abbreviations: BSA, bovine serum albumin; DOX, doxorubicin; NPs, nanoparticles; $\mathrm{V}$, vanillin. 
A
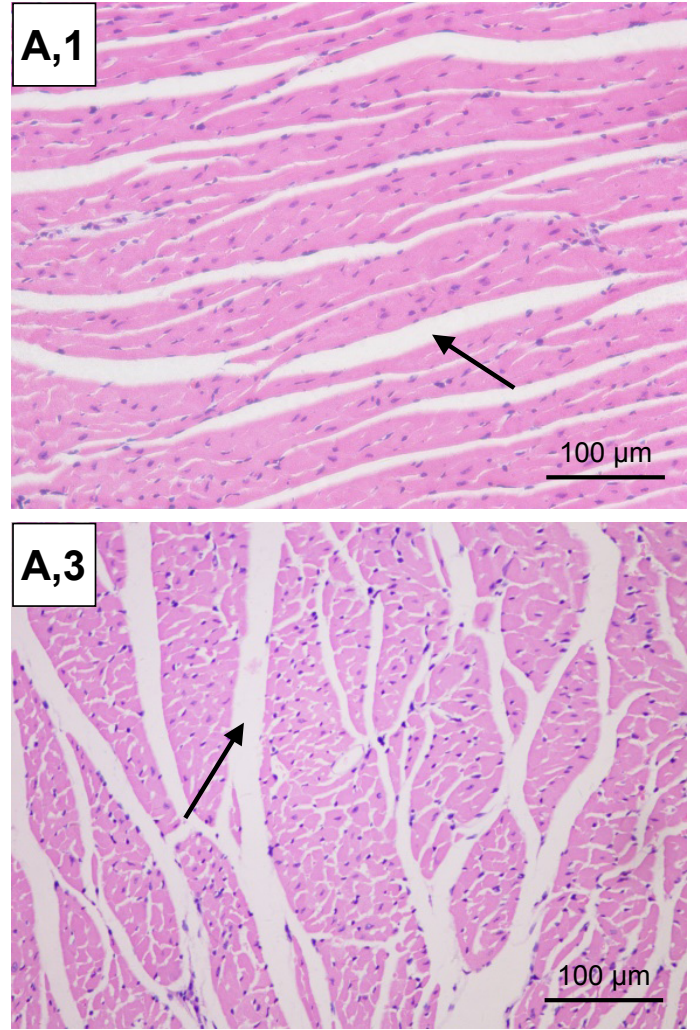

B
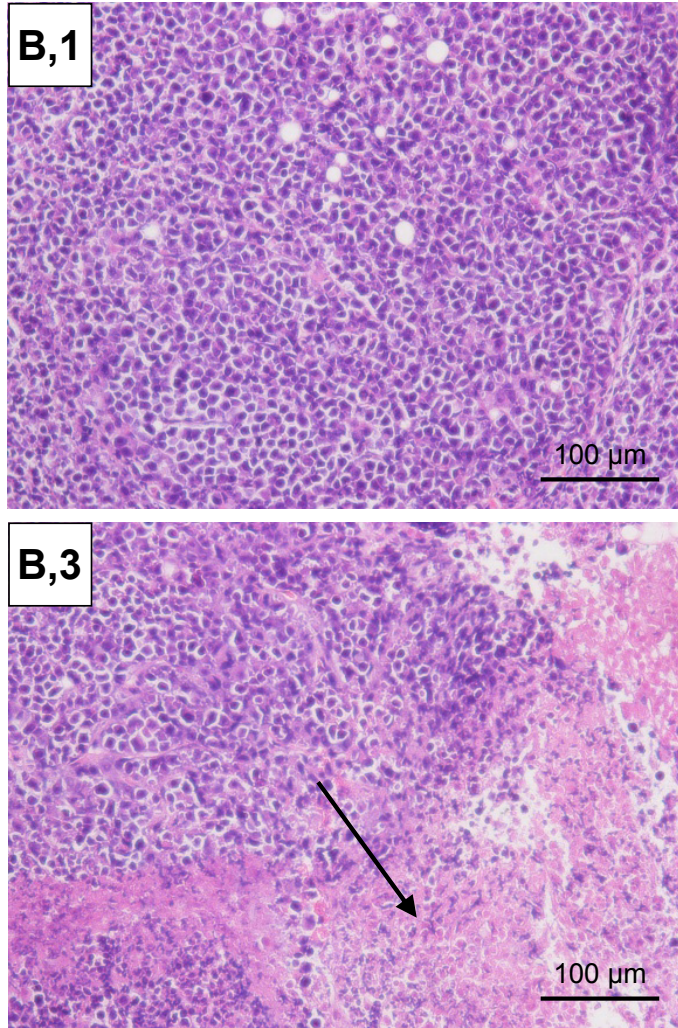
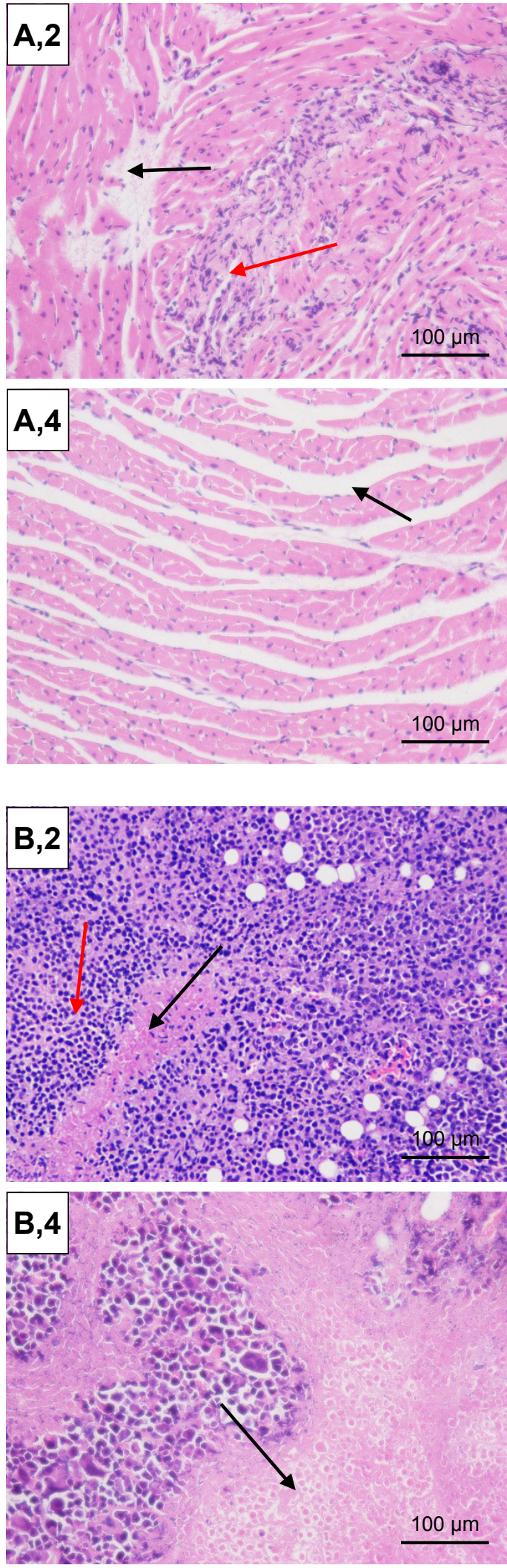

Figure 13 HE staining of (A) heart and (B) tumor (200× magnification).

Notes: Heps tumor-bearing mice were randomly divided into four treatment groups and were administered with (I) normal saline, (2) free DOX, (3) DOX-BSA-NPs, and (4) DOX-BSA-V-NPs. Black arrow in (A,I), myocardial fibers arranged neatly; black arrow in $(\mathbf{A}, 2)$, moderate focal edema necrosis; black arrow in $(\mathbf{A}, \mathbf{3})$ and $(\mathbf{A}, \mathbf{4})$, a slight extension of the myocardial fiber gap; red arrow in $(\mathbf{A}, \mathbf{2})$, focal band fibrosis; red arrow in $(\mathbf{B}, \mathbf{2})$, inflammatory infiltration; black arrow in $(\mathbf{B}, \mathbf{2})$, $(\mathbf{B}, \mathbf{3})$ and $(\mathbf{B}, \mathbf{4})$, cell apoptosis and spotty necrosis.

Abbreviations: BSA, bovine serum albumin; DOX, doxorubicin; HE, hematoxylin and eosin; NPs, nanoparticles; V, vanillin. 


\section{Acknowledgments}

This work was supported by the National Science Foundation of China (No 81402878), the College Graduate Research and Innovation Plan of Jiangsu Province (No CXZZ13_0327), and the Medical Science and Technology development project of Yancheng City (YK2015048).

\section{Disclosure}

The authors report no conflicts of interest in this work.

\section{References}

1. Eatock M, Church N, Harris R, et al. Activity of doxorubicin covalently bound to a novel human serum albumin microcapsule. Invest New Drugs. 1999;17(2):111-120.

2. Singal PK, Iliskovic N. Doxorubicin-induced cardiomyopathy. N Engl J Med. 1998;339(13):900-905.

3. Dreis S, Rothweiler F, Michaelis M, Cinatl J Jr, Kreuter J, Langer K. Preparation, characterisation and maintenance of drug efficacy of doxorubicin-loaded human serum albumin (HSA) nanoparticles. Int J Pharm. 2007;341(1-2):207-214.

4. Peer D, Karp JM, Hong S, Farokhzad OC, Margalit R, Langer R. Nanocarriers as an emerging platform for cancer therapy. Nat Nanotechnol. 2007;2(12):751-760

5. Maswadeh HM, Aljarbou AN1, Alorainy MS, Rahmani AH, Khan MA. Coadministration of doxorubicin and etoposide loaded in camel milk phospholipids liposomes showed increased antitumor activity in a murine model. Int J Nanomedicine. 2015;10:2847-2855.

6. Tardi PG, Boman NL, Cullis PR. Liposomal doxorubicin. J Drug Target. 1996;4(3):129-140.

7. Drummond DC, Meyer O, Hong K, Kirpotin DB, Papahadjopoulos D. Optimizing liposomes for delivery of chemotherapeutic agents to solid tumors. Pharmacol Rev. 1999;51(4):691-743.

8. Harris L, Batist G, Belt R, et al; TLC D-99 Study Group. Liposome encapsulated doxorubicin compared with conventional doxorubicin in a randomized multicenter trial as first-line therapy of metastatic breast carcinoma. Cancer. 2002;94(1):25-36.

9. Hofheinz RD, Gnad-Vogt SU, Beyer U, Hochhaus A. Liposomal encapsulated anti-cancer drugs. Anticancer Drugs. 2005;16(7):691-707.

10. Wang T, Hartner WC, Gillespie JW, et al. Enhanced tumor delivery and antitumor activity in vivo of liposomal doxorubicin modified with MCF-7-specific phage fusion protein. Nanomedicine. 2014;10(2): 421-430.

11. Miolo G, Baldo P, Bidoli E, et al. Incidence of palmar-plantar erythrodysesthesia in pretreated and unpretreated patients receiving pegylated liposomal doxorubicin. Tumori. 2009;95(6):687-690.

12. Gharagozlou M, Boghaei DM. Interaction of water-soluble amino acid Schiff base complexes with bovine serum albumin: fluorescence and circular dichroism studies. Spectrochim Acta A Mol Biomol Spectrosc. 2008;71(4):1617-1622.

13. Akbari Dilmaghani K, Nasuhi Pur F, Hatami Nezhad M. Synthesis and antibacterial evaluation of new thione substituted 1,2,4-triazole Schiff bases as novel antimicrobial agents. Iran J Pharm Res. 2015;14(3): 693-699.

14. Ayodhya D, Venkatesham M, Kumari AS, Reddy GB, Ramakrishna D, Veerabhadram G. Synthesis, characterization, fluorescence, photocatalytic and antibacterial activity of CdS nanoparticles using Schiff base. J Fluoresc. 2015;25(5):1481-1492.

15. Sunil D, Isloor AM, Shetty P, Nayak PG, Pai KSR. In vivo anticancer and histopathology studies of Schiff bases on Ehrlich ascitic carcinoma cells: 1st cancer update. Arab J Chem. 2013;6(1):25-33.

16. Chazin Ede L, Sanches Pde S, Lindgren EB, et al. Synthesis and biological evaluation of novel 6-hydroxy-benzo[d][1,3] oxathiol-2-one Schiff bases as potential anticancer agents. Molecules. 2015;20(2): 1968-1983.
17. Ceyhan G, Köse M, Tümer M, Demirtaş İ, Yağlioğlu AS, McKee V. Structural characterization of some Schiff base compounds: investigation of their electrochemical, photoluminescence, thermal and anticancer activity properties. J Lumin. 2013;143(6):623-634.

18. Carter DC, Ho JX. Structure of serum albumin. Adv Protein Chem. 1994;45:153-203.

19. Li F, Jiang L, Xin J, et al. Preparation and in vitro evaluation of albumin nanoparticles produced by thermal driven self-assembly method. J China Pharm Univ. 2016;47(3):303-310.

20. Hou L, Zhang H, Wang Y, et al. Hyaluronic acid-functionalized singlewalled carbon nanotubes as tumor-targeting MRI contrast agent. Int J Nanomedicine. 2015;10:4507-4520.

21. Jiang $\mathrm{L}, \mathrm{Zhao} X$, Zheng $\mathrm{C}$, et al. The quantitative detection of the uptake and intracellular fate of albumin nanoparticles. RSC Adv. 2015;5(44): 34956-34966.

22. Qi J, Yao P, HeF, Yu C, Huang C. Nanoparticles with dextran/chitosan shell and BSA/chitosan core-Doxorubicin loading and delivery. Int J Pharm. 2010;393(1-2):176-184.

23. Jiang L, Xu Y, Liu Q, et al. A nontoxic disulfide bond reducing method for lipophilic drug-loaded albumin nanoparticle preparation: formation dynamics, influencing factors and formation mechanisms investigation. Int J Pharm. 2013;443(1-2):80-86.

24. Deng W, Li J, Yao P, He F, Huang C. Green preparation process, characterization and antitumor effects of doxorubicin-BSA-dextran nanoparticles. Macromol Biosci. 2010;10(10):1224-1234.

25. Zhen X, Wang X, Xie C, Wu W, Jiang X. Cellular uptake, antitumor response and tumor penetration of cisplatin-loaded milk protein nanoparticles. Biomaterials. 2013;34(4):1372-1382.

26. Ding D, Tang X, Cao X, et al. Novel self-assembly endows human serum albumin nanoparticles with an enhanced antitumor efficacy. AAPS PharmSciTech. 2014;15(1):213-222.

27. Chen Z, Chen J, Wu L, et al. Hyaluronic acid-coated bovine serum albumin nanoparticles loaded with brucine as selective nanovectors for intra-articular injection. Int J Nanomedicine. 2013;8:3843-3853.

28. Xu X, Zhang L, Assanhou AG, et al. Acid/redox dual-activated liposomes for tumor targeted drug delivery and enhanced therapeutic efficacy. RSC Adv. 2015;5(83):67803-67808.

29. da Silva GB, Scarpa MV, Carlos IZ, et al. Oil-in-water biocompatible microemulsion as a carrier for the antitumor drug compound methyl dihydrojasmonate. Int J Nanomedicine. 2015;10:585-594.

30. Wang X, Xie X, Ren C, Yang Y, Xu X, Chen X. Application of molecular modelling and spectroscopic approaches for investigating binding of vanillin to human serum albumin. Food Chem. 2011;127(2):705-710.

31. Ferraro J, Nakamoto K, Brown C. Introductory Raman spectroscopy. 2nd ed. San Diego, CA: Academic Press; 2003.

32. Zhang Y, Huo M, Zhou J, et al. DDSolver: an add-in program for modeling and comparison of drug dissolution profiles. AAPS J. 2010; 12(3):263-271.

33. Bae Y, Fukushima S, Harada A, Kataoka K. Design of environmentsensitive supramolecular assemblies for intracellular drug delivery: polymeric micelles that are responsive to intracellular $\mathrm{pH}$ change. Angew Chem Int Ed Engl. 2003;42(38):4640-4643.

34. Li Y, Budamagunta MS, Luo J, Xiao W, Voss JC, Lam KS. Probing of the assembly structure and dynamics within nanoparticles during interaction with blood proteins. ACS Nano. 2012;6(11):9485-9495.

35. Zhang W, Qiao L, Wang X, Senthilkumar R, Wang F, Chen B. Inducing cell cycle arrest and apoptosis by imercaptosuccinic acid modified $\mathrm{Fe}_{3} \mathrm{O}_{4}$ magnetic nanoparticles combined with nontoxic concentration of bortezomib and gambogic acid in RPMI-8226 cells. Int J Nanomedicine. 2015; 10:3275-3289.

36. Abbad S, Wang C, Waddad AY, Lv H, Zhou J. Preparation, in vitro and in vivo evaluation of polymeric nanoparticles based on hyaluronic acid-poly(butyl cyanoacrylate) and D-alpha-tocopheryl polyethylene glycol 1000 succinate for tumor-targeted delivery of morin hydrate. Int J Nanomedicine. 2015;10:305-320.

37. Wu Y, Chu Q, Tan S, et al. D- $\alpha$-tocopherol polyethylene glycol succinate-based derivative nanoparticles as a novel carrier for paclitaxel delivery. Int J Nanomedicine. 2015;10:5219-5235. 


\section{Supplementary material}

Table SI P-values calculated by one-tailed t-test

\begin{tabular}{llll}
\hline Group & Free DOX & DOX-BSA-NPs & DOX-BSA-V-NPs \\
\hline Normal saline & 0.124 & 0.0141 & 0.00139 \\
Free DOX & & 0.0419 & 0.00291 \\
DOX-BSA-NPs & & & 0.0476 \\
\hline
\end{tabular}

Abbreviations: BSA, bovine serum albumin; DOX, doxorubicin; NPs, nanoparticles; V, vanillin.

\section{Publish your work in this journal}

The International Journal of Nanomedicine is an international, peerreviewed journal focusing on the application of nanotechnology in diagnostics, therapeutics, and drug delivery systems throughout the biomedical field. This journal is indexed on PubMed Central, MedLine, CAS, SciSearch ${ }^{\circledR}$, Current Contents ${ }^{\circledR} /$ Clinical Medicine,
Journal Citation Reports/Science Edition, EMBase, Scopus and the Elsevier Bibliographic databases. The manuscript management system is completely online and includes a very quick and fair peer-review system, which is all easy to use. Visit http://www.dovepress.com/ testimonials.php to read real quotes from published authors.

Submit your manuscript here: http://www.dovepress.com/international-journal-of-nanomedicine-journal 